\title{
Environmental management in China
}

Victoria Karlsson

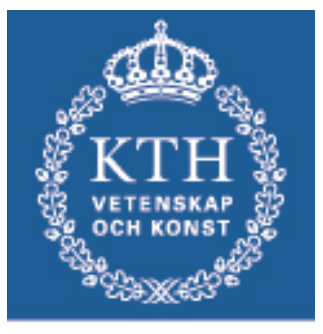

ROYAL INSTITUTE OF TECHNOLOGY

\author{
Master of Science Thesis \\ Stockholm 2010
}





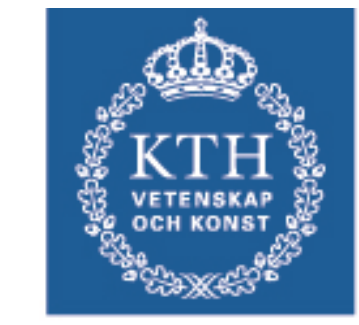

KTH Industrial Engineering and Management

Victoria Karlsson

\section{Environmental management in China}

Supervisors:

Nils Brandt

Dave Million

Jan Stighagen

Examiner:

Nils Brandt

Master of Science Thesis 
TRITA-IM 2010:04

ISSN 1402-7615

Industrial Ecology,

Royal Institute of Technology

www.ima.kth.se 


\section{Environmental management in China}

Student:

Victoria Karlsson, vkar@kth.se victoria.carlsson@volvoce-china.com

Supervisors:

Nils Brandt, nilsb@kth.se

Dave Million, dave.million@volvo.com Jan Stighagen, jan.stighagen@volvo.com 


\section{Acknowledgements}

First of all I would like to express my appreciation towards Volvo Construction Equipment and Klas Magnusson who helped me with the contact at VCE Shanghai. I want to thank my supervisors Dave Million (VCE Shanghai/Lingong), Jan Stighagen (VCE Sweden), and Nils Brandt (Royal Institute of Technology) for making this research possible.

Having the opportunity to study Environmental Management Systems in a company as Volvo $\mathrm{CE}$ for six months was a unique chance and source of priceless experience for me. I am grateful to Elisabeth Altin (VCE Sweden) for giving me input, feedback, and helping me with contacts along the journey. Without her guidance and support this research would not have been possible. I want to give my sincere gratitude to the VCE plant in Shanghai for all the assistance I got during my work. In specific I want to express my appreciation to Phil Chen and Benoit Rimaz. I would also like to express gratitude to Shandong Lingong and all the helping people there, among others; Mr Wen, Mr Wang, and Kathy Song.

Last, but not the least, I want to thank all the people I made interviews with; Bleuenn Carre (JEC Environmental Consultant), Aurore Naudin (Tongji University), Samantha Rens (Idrabel Environmental Technology), Jack Chen (SGS), Lewis Wu (SKF), and Hans Kjelltorp (Sandvik).

Victoria Karlsson

Frösakull 2009 


\section{Abstract}

In this study the aim was to investigate and nuance how the Volvo Construction Equipment (VCE) production Hub can evolve their environmental work, at Chinese wheel loader producer Shandong Lingong (SDLG), to reach Volvo standard. The study also aimed to investigate what international companies in China should take into consideration in their environmental work. The work was carried out by answering the following research questions; In which way or ways can the VCE Hub at SDLG evolve their environmental work to reach Volvo standard? What should international companies take into consideration in their environmental work when establishing on the Chinese market, and why?

A lot of the information in this Thesis is based on empirical data, i.e. interviews. Three interviews with Swedish companies have been carried out. They are all highly valuing Environmental work but use different methods, their situations are unlike and they produce diverse products. Several interviews with people working with environmental issues in different ways have also been done, as well as with the SGS; a Chinese certification body. Three different companies with production in or around Shanghai were chosen; Volvo CE, SKF, and Sandvik. All three companies are originally Swedish but with production in China. Environmental work is highly prioritized in Sweden and the companies have global environmental policies and goals. The three companies were chosen because they are in different production areas but they are striving in the same direction with environmental issues in China. They are working differently and their situations are of various kinds. In 2006 Volvo $\mathrm{CE}$ invested in a Chinese wheel loader producer named Shandong Lingong. Volvo CE has a Hub, at the plant, which runs independently. SDLG are still not ISO 14001 certified and do not have an environmental management system (EMS) that is conformably with the Volvo demands.

The most important to take into consideration when doing business in China is according to the study; top management support, to do training for the employees, mediate the importance of awareness, and to have knowledge about Chinese regulations. These are some of the issues International companies have to deal with when doing business in China. A well established EMS is a necessity for a good environmental work. To implement an EMS in the Hub as a pilot project is the best solution according to the information gathered in this thesis. SDLG could be a part-, they can evaluate-, and later it could be possible to implement the process in the whole SDLG. Due to this methodology they will learn how to work according to Volvo requirements and obtain benefits of an implementation. There are three different alternatives for the ISO 14001 certification of the Hub according to this work. For the Hub to be ISO 14001 certified together with another Volvo plant seems to be the best alternative thought it reduces the amount of work with legal authorities. VCE's EMS will also not be compared with SDLG and it will be moneysaving. The policies and Environmental aspects (EA) though have to be rewritten to be suitable for both the factories.

Keywords: China, ISO 14001, Environment, Environmental management systems (EMS), Volvo Construction Equipment (VCE), Shandong Lingong (SDLG). 


\section{Table of Content}

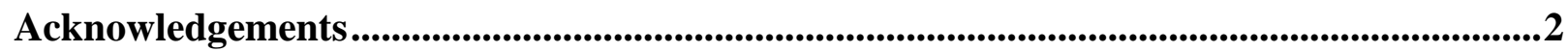

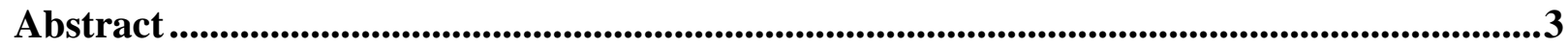

1. Introduction ............................................................................................................................

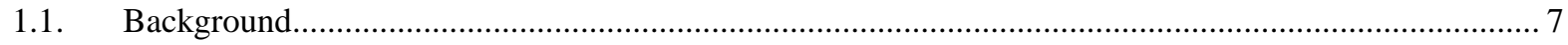

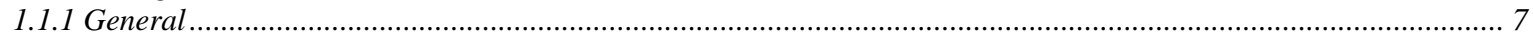

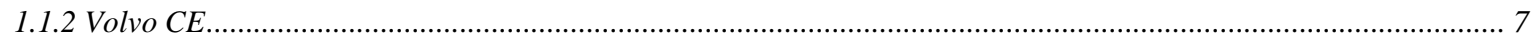

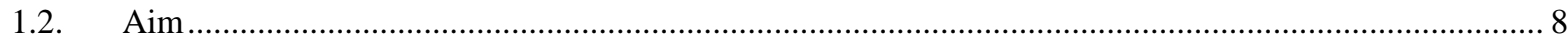

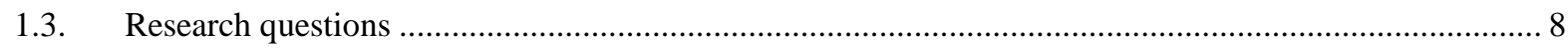

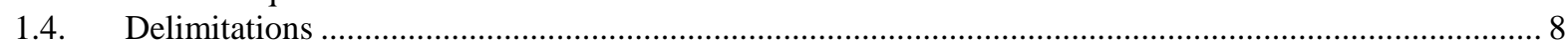

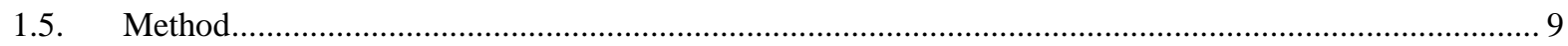

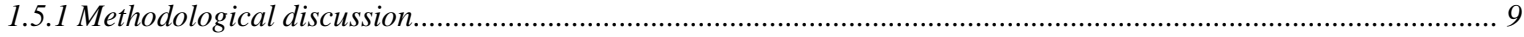

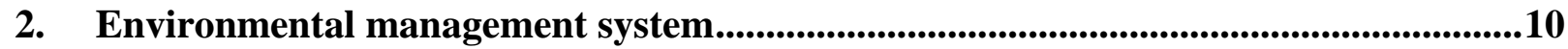

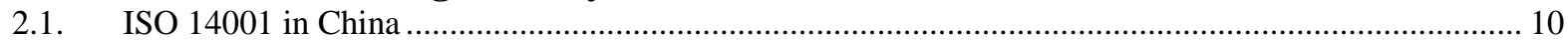

2.1.1 Background institutions …………………………………………………………………………….... 10

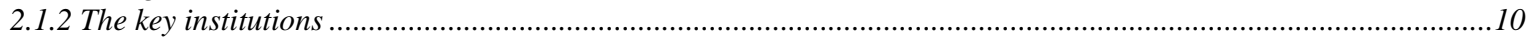

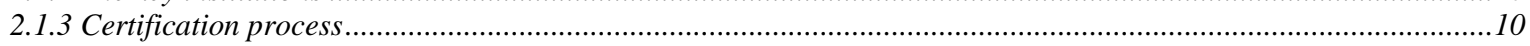

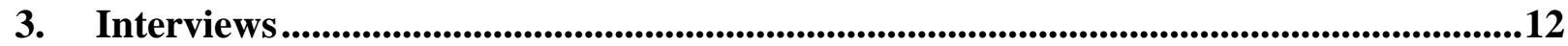

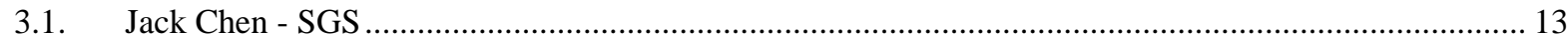

3.2. Samantha Rens - Idrabel Environmental Bio Tech............................................................................ 14

3.3. Bleuenn Carre - JEC Environmental Consultant ............................................................................. 15

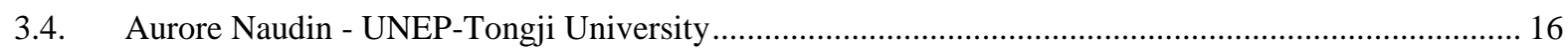

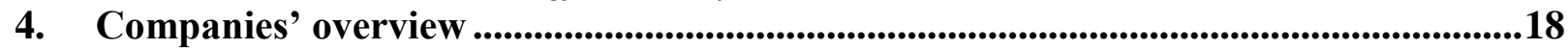

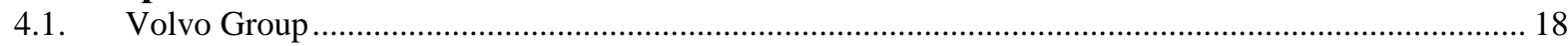

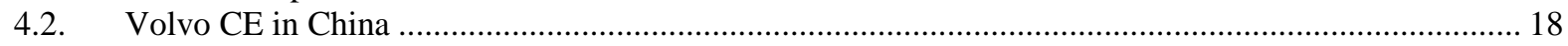

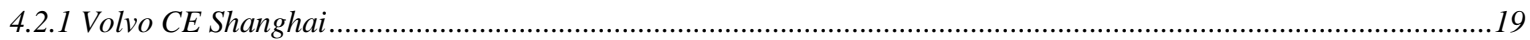

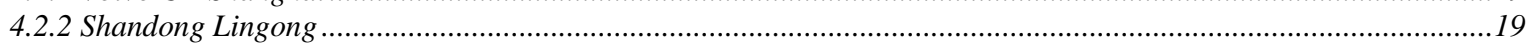

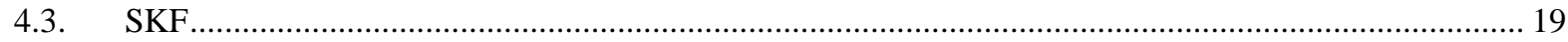

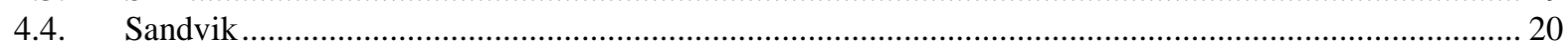

5. Volvo wanted position and guidelines ..............................................................................21

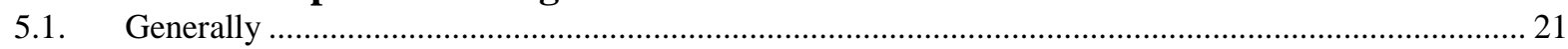

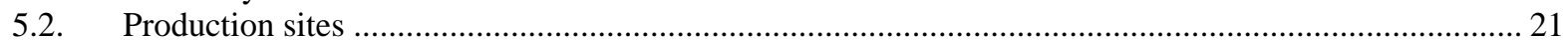

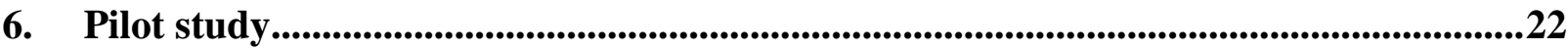

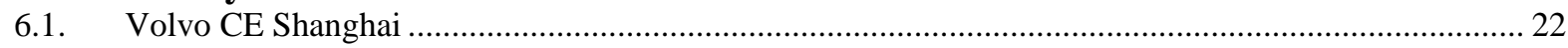

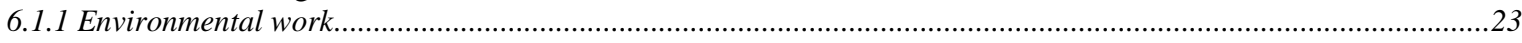

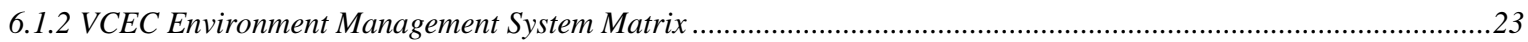

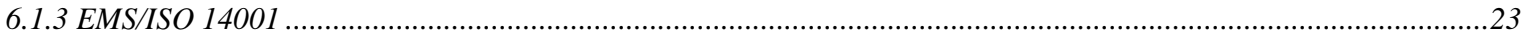

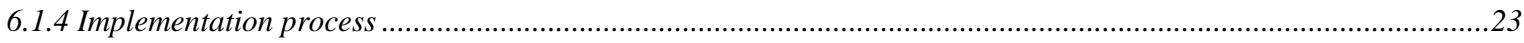

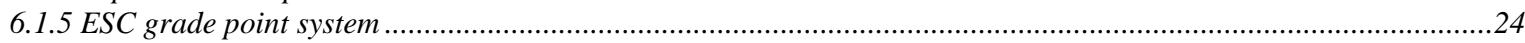

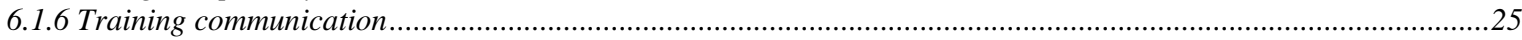

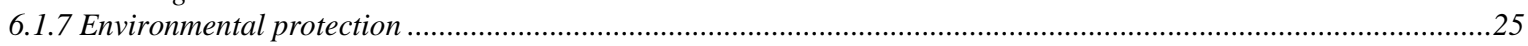

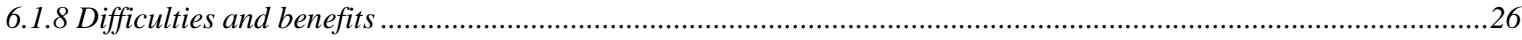

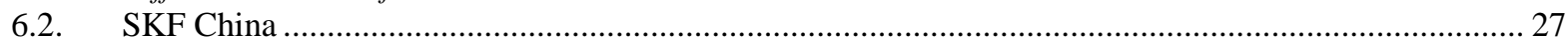

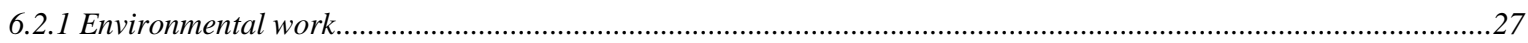

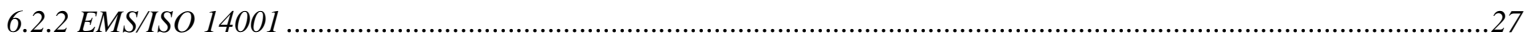

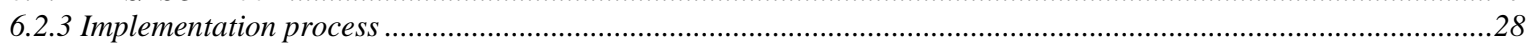

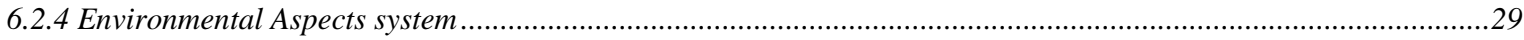

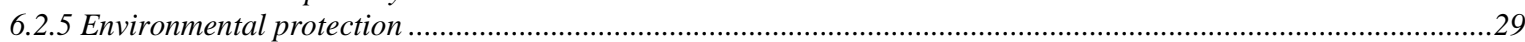

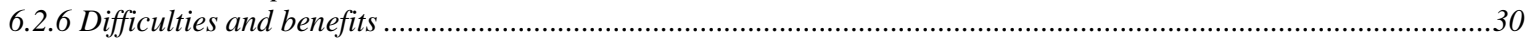

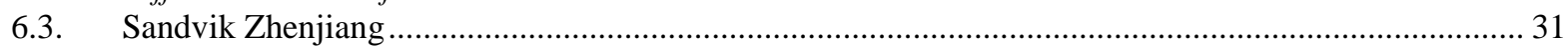

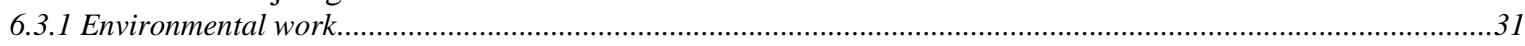

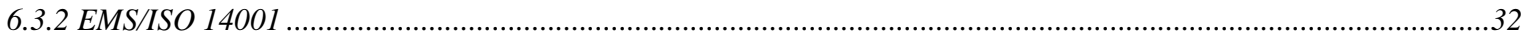

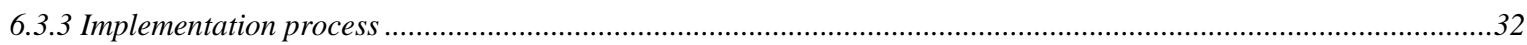

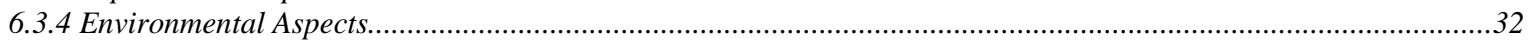

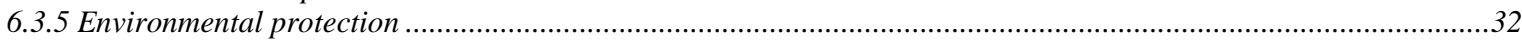

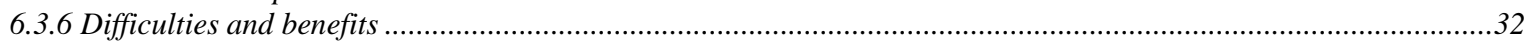

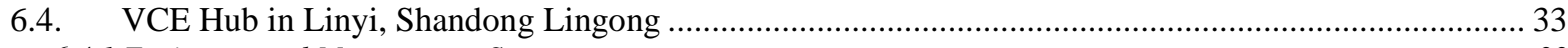

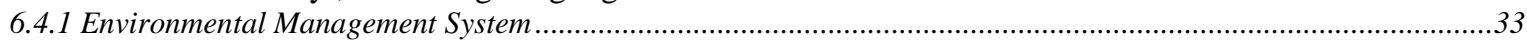

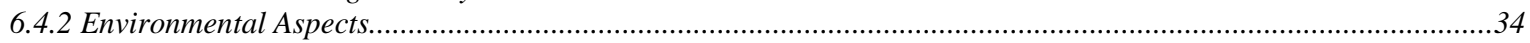




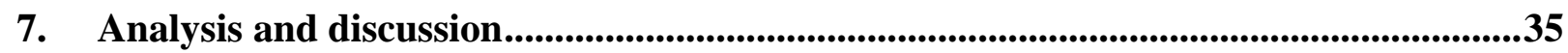

8. Conclusion.......................................................................................................................................41

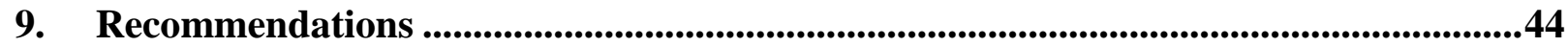

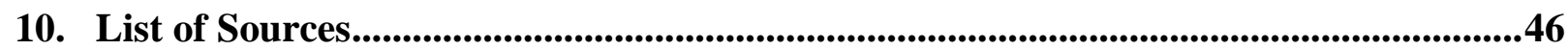

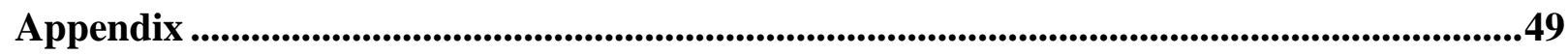

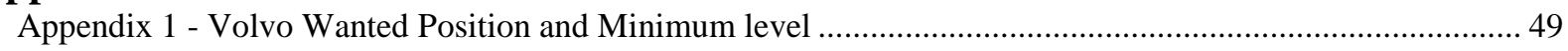

Appendix 2 - VCEC Environment Management System Matrix ……………................................................ 52 


\section{Acronyms}

CCAA

CNAB

CNAT

EMS

ISO

JV

MR

SDLG

SE

SEPA

TQM

UNEP

VCE

VCEC
China Certification \& Accreditation Association

China National Accreditation Board for Certifiers

China National Auditor and Training Board

Environmental Management System

International Standard Organization

Joint Ventures

Management Representative's

Shandong Lingong Construction Machinery Co., Ltd

Safety \& Environment

State Environmental Protection Administration

Total Quality Management

United Nations Environmental Programme

Volvo Construction Equipment Ltd

Volvo Construction Equipment Shanghai 


\section{Introduction}

\subsection{Background}

\subsubsection{General}

More and more international companies invest in Chinese companies. The fast development, in combination with wanting knowledge about the consequences, has resulted in extensive contamination and wear on the environment (www.swedishtrade.se, 2009). It is of great concern that all international companies precede with highly value in their environmental work. A problem for international investers is that some Chinese companies still do not care or do not have the knowledge about social responsibility in business. The consumers claim that the companies should take their social and environmental responsibility. Companies on the other hand claim that the average consumer is not willing to pay the extra cost for a product produced in China that meets international environmental standards. While investors claim that their suppliers must fulfill some demands; a new way of working and new ideas are implemented. (www.swedishtrade.se, 2009) To understand the issue it is of great concern to have knowledge about environmental work in China today. It should be of great value that all international companies invest in China with a high regard for environmental concern. Environmental management is a highly prioritized topic for most companies today and it is important that it works worldwide. How the environmental management should be handled and what rules that should be followed, varies between different companies. It is important to have demands that should be followed but also to have a wanted position to strive for. International Standard Organization 14001 (ISO 14001) is a well established international environmental standard, and most companies struggle to meet its demands. ISO 14001 does not have a strict level that companies have to obtain to be certified, though it stands for active environmental work and continuous improvements (Brorson \& Almgren, 2007). Most of the Chinese companies do not have the same standards and the same environmental demands as international companies. Outgoing from this it is important to highlight if/how international companies, with activity in China, can influence domestic companies enhancing their environmental work.

\subsubsection{Volvo CE}

Shandong Lingong Construction Machinery Co., Ltd. (SDLG) is situated in Linyi, has around 2200 employees, and is producing SDLG branded wheel loaders, compact excavators, and compactors. The industrial facility contains 12 assembly and fabrication workshops. (Wang J., 2009) Volvo invested in Lingong in 2006 to create a Joint Ventures (JV) with Volvo as majority shareholder. The company still manages its own manufacturing of components, assembly line, and manages operations independent from Volvo. Volvo CE though has a hub in a separate building of the plant, with an assembly line and that part is managed by Volvo themselves. There is no manufacturing in the hub; therefore all components are bought from companies all round in China, and internationally. Only a small fraction is from the production of the SDLG plant. The Volvo plants all around the world should obtain certifications in ISO 9000, 18000 and ISO 14001 (Million 2009). SDLG are aware of the importance of a 
certification, and will start the investigative work for ISO 14001 certification process from March 2009 until October 2009. SDLG expect to be certified during 2010 (Lu 2009). The actual situation at the SDLG plant does not reach Volvo environmental standard; but is thought to meet Chinas national standards. By meeting this standard the SDLG facility will meet ISO 14001 criteria but in all likelihood will be below the international standard and certainly far away from Volvo's "Wanted Position". The interesting part is; will SDLG reach the Volvo acceptable environmental level even after they have been certified?

Volvo has a plant in Shanghai, with around 250 employees, producing excavators Volvo (Volvo internal, 2009). This plant has been certified since 2006, has a high environmental standard, and a well working EMS (Altin 2009). How the Shanghai plant, and other international companies in China, implemented their EMS and how they work with continuous improvement could be of high value for the Volvo Hub in Linyi.

\subsection{Aim}

The aim of this Master Thesis was to investigate, analyze, and discuss how the VCE Hub at Shandong Lingong can evolve their environmental work to reach Volvo standard. In a broader perspective this study also aimed to investigate what international companies in China should take into consideration in their environmental work.

\subsection{Research questions}

1. In which way or ways can the VCE Hub at Shandong Lingong evolve their environmental work to reach Volvo standard?

2. What should international companies take into consideration in their environmental work when establishing on the Chinese market, and why?

\subsection{Delimitations}

The work was delimitated to contain the Volvo Hub at the SDLG plant in Linyi, and the Volvo CE plant in Shanghai, China, this due to limits in time. Interviews with other international companies and people working with environmental related issues were also done in order to get a wider range of knowledge. Some sources that are used in this report were only published in Chinese and had to be translated, therefore some of the terms may have been inaccurately translated. 


\subsection{Method}

The work was divided in two parts. The initiated and major part was done in Shanghai and Linyi, China, and the second part was carried out in Stockholm, Sweden. The work contains a literature study of how the certification process is carried out in China. Factory visits, interviews and surveys were carried out in order to find out how plants in the Shanghai region has done, how the actual situation is at the hub in Linyi, and what the plans are for working with environmental questions in the future.

\subsubsection{Methodological discussion}

According to McCracken (1998) there are several major differences between a qualitative and a quantitative perspective on research. The quantitative goal is to isolate and identify categories as accurately as possible before the study is undertaken, and then to determine, with great exactness, the relationship between them. On the other hand, the qualitative studies goal is to define and isolate categories ongoing in the research process. Kvale (1996) argues that qualitative and quantitative research methods are tools, tools whose beneficial effects depend upon their power to bear the posed research question.

In this study a qualitative research method were applied for a variety of reasons. In order to answer the research questions non quantified data was needed, e.g. values and attitudes. Qualitative research endows the opportunity to investigate and analyze selected issues in depth and in detail, which would not be possible to achieve by using a solely quantitative study focusing on causal relationship (Kvale 1996). The qualitative research approach rather focus on exploring how and why questions. As such, focus lied in explaining phenomenon's - how the VCE Hub at Shandong Lingong can evolve their environmental work to reach Volvo standard and what international companies in China should take into consideration in their environmental work.

Data used for research that was not gathered directly and purposefully for the project under consideration is called secondary data. As with all data collected for research purpose there are a number of both advantages and disadvantages. The greatest disadvantage with secondary data is, according to Page et al. (2007), that the data could be misaligned to the specific purpose of the study. In this research it has been rather hard to find striking external secondary data due to the complexity of the research problem. However, another form of secondary data is internal data. Internal secondary sources of information can be categorized as data that are published within a company or organization, such as annual reports, information booklets, and company brochures. In this study a great deal of internal secondary data where used, foremost documents highlighting environmental issues at Volvo. (Page et al., 2007).

Primary data can be described as data that is collected specifically for the specific research. In this research the primary data where conducted through interviews, documentations and observations. 


\section{Environmental management system}

\subsection{ISO 14001 in China}

\subsubsection{Background institutions}

China started to develop its environmental labelling system in the beginning of 1990. Cleaner production and waste minimisation were introduced and practiced, and it enabled to introduce EMS standards based on ISO 14001. China Steering Committee of Environmental Management Systems Accreditation was established by the State council in Beijing in 1997. Its office was located in State Environmental Protection Administration (SEPA). The committee was responsible for ISO 14001 implementation and certification, and also for the administration and EMS certification, in China. The committee contained two working groups; China Accreditation Committee for Environmental Certification Bodies (CACEB) and China Registration Committee for Environmental Auditor (CRCEA). CACEB was responsible for the approval and accreditation of EMS certification bodies, CRCEA was responsible for the approval and registration of environmental auditors, and the EMS training institutions. ISO 9001 implementation and certification were working on with a similar system and it was later merged together with the system for ISO 14001. After the merge the two working groups were called China National Accreditation Board for Certifiers (CNAB) and China National Auditor and Training Board (CNAT). (Chen J., 2009) In year 2005 another change were made with the fusion of CNAB and CNAT, which became China Certification \& Accreditation Association (CCAA). (www.ccaa.org) There were 28 certification bodies and 3834 environmental auditors in China in the end of 2001 and ISO 14001 certificates were given to 1024 organisations in total. (www.unep.or, 2009)

\subsubsection{The key institutions}

CCAA was founded in 2005 after the fusion of CNAB and CNAT. It is a non profit and national organization that intends to advance the development of the accreditation and certification industry. CCAA provide services of all kinds for government, industry, and society. Some of the main duties are to provide policy and legislation suggestions for the government, to publish standards, material relevant to certification, and to register among others auditors in EMS; Certification bodies (CB). (www.ccaa.org, 2009) Some of the largest CB' working in China are SGS, DNV, BSI, BVC (fd BVQI), and TUV. (Chen P., 2009)

\subsubsection{Certification process}

To apply for a certification an organisation must have had an EMS established and operated for a minimum of three months. The organisation also has to comply with national and local environmental laws, regulations and requirements. The organisation themselves decide the certification bodies and consulting institution filed.

When the organisation would like to apply for auditing and certification they have to submit the following documents to the certification body;

- Data of the past year' pollutant discharges, the document has to be issued by the environmental monitoring agency. 
- A document proving that the organisation for the past year has not been punished upon violation of environmental laws and regulations. This document also has to be provided by environmental authority on at least city level.

The audit, done by the certification body, will be carried out in two phases. When both the audit on EMS documentation and the on-site audit are done, then the certification body will provide a technical review and report. CNAB will evaluate the report for further review and filing. A certification is valid for three years from date of issuance. (www.unep.or, 2009) Every third year a renew audit has to be carried out. This is also done by the $\mathrm{CB}$ and on the purpose of checking that all legal requirements can be confirmed and the fulfilling of policies and objectives. The CB will after the renew audit give audit findings and suggestions, if there are some minor problems discovered the company have to carry out an Action plan and send to the CB. The plan should be sent within one month, though the company still keep their certification. If there are some major problems an Action plan has to be sent in three month, though the certification will still remain. If larger problems are found the company have to execute the situation before applying for a new audit. (Chen J., 2009)

\section{Opinions according to SGS Shanghai Audit team}

According to the interviewed persons, Jack Chen and his audit team, there is a difference in attitude between International companies/JV and Chinese companies. The last mentioned seems to be more obstructed when it comes to sharing information and sometimes more for cosmetic things than set about the actual problem. (Chen P., 2009) The important base to all work with EMS and ISO certification is the environmental aspects. It is based from where a sustainable EMS is build and it is also the starting point for the Audit team when evaluating a company' environmental work. The two keywords are according to an SGS audit leader; Top management and Environmental Aspects. (Chen J., 2009)

\section{Opinions according to DNV}

Contact was taken by e-mail with DNV to get the opinion of another large CB. However no answer has been received. 


\section{Interviews}

Interviews were carried out in order to get a wider range of empirical knowledge about the environmental situation in China today. The four persons that were interviewed have different backgrounds but are all working with environmental related issues in China. Below is a summarized selection of citations from the interviews:

"I see that it is much more important for international companies to obey the rules than the Chinese ones"

- Samantha Rens, Idrabel Environmental Biotechnology

"Keywords: international standards, transparency, respect of individuals and of the nature." - Bleuenn Carre, JEC Environmental Consultant

"The more international companies and foreigners come to China, the more China and Chinese people are open to the world and have to face their responsibilities."

- Samantha Rens, Idrabel Environmental Biotechnology

"Let us not forget that the international companies were far from being environmental models until it recently became an asset for their business strategies/plans and pressure of the civil society of governmental regulation."

- Aurore Naudin, Student Tongji University

"The staffs in good International companies get training, knowledge, and their attitude could change. These new experiences could be brought back to the domestic companies later on."

- Jack Chen, SGS China

"Lots of research, experiment, political will as well as society awareness are needed to adapt and implement sustainable development in China."

- Aurore Naudin, Student Tongji University

"The money that is being invested in the environment is usually not followed or the money gets lost in officials pockets"

- Samantah Rens, Idrabel Environmental Biotechnology 


\subsection{Jack Chen - SGS}

Jack Chen is an Audit leader at the certification body SGS in Shanghai China. Jack was in charge for the ISO 14001 Audit at Volvo CE Shanghai, Mars 2009. The interview was carried out in order to get more knowledge about the difference between domestic and international companies' environmental work in China. A certification body is an excellent organization to interview, since they are neutral and have looked into many different companies.

Is there a difference between certifying domestic companies compared to international companies? If there is; then what is the difference in attitude, action etc.?

"Domestic companies are working passive to keep the law, though good International companies are instead working active to keep the law. Domestic companies have more often less input of resources for the work with Environmental Management System while good International companies' input is more sufficient."

What are the most common problems in companies' environmental work and what are they usually best at?

"The positive aspects are energy saving and could also be to abide by the law. Negative aspects could be the premise of the law-abiding, that the emission reduction is not very active, such as the emission of wastewater, waste gas, and solid waste."

What do you think about the mentality for environmental questions in China overall? Is there a positive trend? What has to be done for the future?

"Most companies could meet the legal requirements today; some are also on a much higher level. Not all International companies meet the requirements. The trend is positive, especially if you look into a time range of two decades. A lot of improvements have been done and the challenge is to stick to the commitment."

Do you think that International companies can have a positive effect on Domestic companies' environmental work?

"International companies which are positive towards environmental work can for sure bring a positive effect on Domestic companies. The staffs in good International companies get training, knowledge, and their attitude could change. These new experiences could be brought back to the domestic companies later on."

What are the most important things (Keywords) to think about when implementing an EMS in a Joint Venture, according to you?

"Awareness and attitude of Top Management." 
International companies responsibility to balance profit against the environmental issues?

"The answer is affirmatory, all of companies located anywhere in the world have to think about the Environmental issues. Companies cannot only think of their own interests anymore and leave for example the pollution problem. The legal requirements are the basic requirements and are all companies' responsibility."

\subsection{Samantha Rens - Idrabel Environmental Bio Tech.}

Samantha Rens is a Belgian woman and Project Coordinator at Idrabel Environmental Biotechnology in Shanghai. The company is working with environmentally friendly solutions for wastewater, an organic product for the cleaning process. The interview was carried out in order to get an understanding about the opinion of people working with environmental questions in China. Samantha works with introducing an organic product to companies, and meets therefore many people and hears different opinions and attitudes. Thus, she is an excellent person to interview about the environmental situation in China and the difference between Domestic and International companies environmental work.

How is the environmental situation in China today and compared to before? What are the future prospects?

"The environment is definitely getting worse and worse as more people are having access to cares, fridge, TV etc. and the consumption of oil, electricity etc. is only going to increase. The central government has certainly understood that it had to take measures to counter the environmental degradation. According to me the main problem is that even though important and good decisions are taken at the central government level, because of the corruption, the rules or money that is being invested in the environment is usually not followed or the money gets lost in officials pockets."

What is the highest prioritized environmental duty that International companies have in China?

"International companies in China have all the eyes on them, they pay a lot of attention to what the world and China has to say about them. In my work field, I see that it is much more important for international companies to obey the rules than the Chinese ones, so in a way they are showing the example, and hopefully the Chinese ones will follow. "

Is there a difference between Domestic and International companies in their environmental work and basic outlook?

"International companies understand that taking the environmental issue into consideration is an absolute necessity now, even for their economic gains. I met with someone from a company in Shanghai awhile ago and he said that they were interested in our "environmentally friendly " solution for their water even if we did not cut any cost, as from a year or two, environmental protection is more important than financial gains. For the moment the image they show the world of themselves is more important than the financial gains." 
Could International companies affect Domestic companies in a positive way?

"I would like to believe so, as the more international companies and foreigners come to China, the more China and Chinese people are open to the world and have to face their responsibilities."

\subsection{Bleuenn Carre - JEC Environmental Consultant}

Bleuenn Carre is a French woman and Project Assistant at JEC Environmental Consultant in Shanghai. The company is working with Greenhouse Gas Mitigation Consulting, Project Planning and Management, and Technology Transfer. The interview was carried out in order to get an understanding about the opinion of people working with environmental questions in China. Bleuenn is a former journalist who now works with a verity of environmental projects. Both today and in her former career she have met a lot of people and heard different opinions and attitudes. She is therefore an excellent person to interview about the environmental situation in China and the difference between Domestic and International companies environmental work.

How is the environmental situation in China today and if you compare to before? What are the future prospects?

"There are absolutely some improvements made in China, such as the separate bins in the street and the advertisements everywhere. For the industrial processes though, the environmental decisions are political. Made by Beijing Government and not by the common people, these policies are very limited and not enough respected, because not requested by the Chinese."

What is the highest prioritized environmental duty international companies have in China?

"Keywords: international standards, transparency, respect of individuals and of the nature."

Is there a difference between Chinese and international companies in their environmental work and basic outlook?

"I do not have very much experience about international companies in China and will take our own company as an example. From the beginning, our company followed some general rules promoting the energy saving from our equipments (copying machine, computers, lights etc.), underlining that our CDM projects' mission is not only a job but has also a meaning in our everyday life. We have no idea about what is going on after 2012 for our company, so the outlook is just for a few years, but we are convinced that this environmental business will flourish in China." 
Could International companies affect Chinese companies in a positive way?

"My boss is Chinese, but has been working in Japan for a long time. Very impacted by this experience, he is trying to carry out the international values of team working, foreign courteousness etc. in our company. He also bought all the foreign shares of the company, which is a $100 \%$ now (and used to be a Japanese company before). This shows that, ok, the international companies may have something to teach us. But that is all, we are not going to follow them blindly, we just pick up what we need and stay Chinese.

Clean development mechanism is one way of helping the developing countries with their environmental problems. Is there the same kind of work for other fields than GHG?

"I am not so knowledgeable about other programs from the UN or other international organisms. But for Chinese government, a lot is done for water resources, forests, energy saving, and autonomy."

China a growing market; is the regulations and requirements for building new plants enough for a sustainable development?

"Of course not. The expected new plants capacity for the next years is not going to meet all the internal growing demands. The regulations would be enough if every Chinese was obliged today to follow these rules. But nowadays, regulations are still reinforced; hope it will be enough one day."

\subsection{Aurore Naudin - UNEP-Tongji University}

Aurore Naudin is a French woman studying Sustainable Development and Environmental Management, at UNEP-Tongji University, Institute of Environment and Sustainable Development in Shanghai. The interview was carried out in order to get the opinion of other students in China studying subjects closely related to my thesis. Aurore is an energetic person, always searching for new knowledge, and she is working part time in a cultural office $(\mathrm{A}-\mathrm{Z})$ promoting sustainable development and cultural diversity. She is in charge of selecting Chinese candidates for a life sustainability awards. Hence, she has knowledge about the environmental work in China and its relation to International companies.

How is the environmental situation in China today and compared to before? What are the future prospects?

"Deteriorating, but awareness is rising and measures are being taken; such as more regulations for national industries as well as for international companies, education, and research. Relocation of Chinese polluting industries to Africa, as Western countries did 10 years ago in Asia. Strategy is to continue exploiting natural resources without deteriorating China's own natural resources and ecosystems." 
What is the highest prioritized environmental duty that International companies have in China?

"Ensure the renewability of natural resources."

Is there a difference between Domestic and International companies in their environmental work and basic outlook?

"Chinese companies might not yet be so sensitive to the environmental protection argument. The main argument for their environmental switch would be cost efficiency. I heard recently a consultant saying that there is clearly a cultural difference for the same environmental approach. To be clear, the concept of environmental responsibility does not mean much for the Chinese, because they see themselves as part of nature rather than actors. However, the key word would be to talk about environmental and human, rather than responsibility."

Could International companies affect Domestic companies in a positive way?

"To a certain extent, their own environmental internal regulation might influence in a positive way, unless it is green washing policies. Let us not forget that the international companies were far from being environmental models until it recently became an asset for their business strategies/plans and pressure of the civil society of governmental regulation."

Clean development mechanism is one way of helping the developing countries with their environmental problems. Same kind of work for other fields than GHG?

"To my knowledge, there is no other market mechanism in other fields than GHG. However, international cooperation, NGO's, and other "unmarketed" structures and strategies are helping a lot; for example technology transfer, volunteering, knowledge, and training."

China a growing market; is the regulations and requirements for building new plants enough for a sustainable development?

"Of course not. Sustainable development means no adverse effect, no natural depletion for it environmental pillar. It is not only mitigation but firstly prevention and substitution. Sustainable development is still at an experimentation stage, it is a culture too that needs to be deeply rooted. China is huge. Lots of research, experiment, political will as well as society awareness are needed to adapt and implement sustainable development in China in a genuine sustainable way. Bad news: China should avoid the implementation of a consumption society and its culture in China; it will be too massive to sustain itself." 


\section{Companies' overview}

Three different Swedish companies were chosen for a pilot study; Volvo CE, SKF, and Sandvik. These are large multinational companies with activities in China. They all work actively with environmental issues and sees sustainability as a prioritized part of their business strategy. They also have a similar background as they are Swedish companies that are relatively new on the Chinese market.

\subsection{Volvo Group}

The Volvo Group was founded in 1927. The organization have sales in 180 markets, production in 19 countries, and about 102000 employees. The business areas within the Volvo Group are Volvo Trucks (medium heavy to heavy trucks), Renault Trucks, Mack Trucks, Nissan Diesel, Construction Equipment, Buses, Volvo Penta, Volvo Aero, and Financial Services. The company is Europe's largest and the world's second largest producer of trucks with the brands Mack, Nissan Diesel, Renault Trucks, and Volvo. The Group of companies is the World's second largest producer of buses with the brands Volvo, Prevost, and Nova bus. Volvo Construction Equipment is one of the leading producers in their business, Volvo Penta is one of the world leading suppliers of engines drive systems for marine and industrial applications, and Volvo Aero is world leading in service and selected components for the air industry. Volvo Financial Services run operations in customer and dealer financing for the Group's business areas and brands. As support for the Business areas activities there are a number of business units; Volvo 3P, Volvo Power Train, Volvo Parts, Volvo Technology, Volvo Logistics, and Volvo IT. The Volvo Group of companies has grown very fast the recent years. Renault Trucks and Mack Trucks were purchased in 2001. In 2006 and 2007 the Japanese truck manufacturer Nissan Diesel was bought, also $70 \%$ of the market share in one of Chinas largest wheel loader producers Lingong and the American company Ingersoll Rands division for road construction machinery was purchased. Since the year 2000 the group of companies has doubled their net sales; in 2004 the sales reached the amount of 200 billion and in 2007 the amount has raised to well over 285 billion. (Volvo internal, 2009)

The Volvo Group vision is "To be valued as the world's leading supplier of commercial transport solutions". It has a Wanted position to struggle; "Number 1 in image and customer satisfaction, Sustainable profitability above average, Number 1 or 2 in size or superior growth rate" (Volvo internal, 2009)

\subsection{Volvo CE in China}

Volvo CE facilities in China are located in Jinan, Linyi, and Shanghai. In Jinan a Research and development (R\&D) office is situated, but no production. The Shanghai plant was founded in 2003 and is producing excavators. In 2006 Volvo CE invested in the company SDLG in Linyi, which is producing Wheel loaders (Excavators) and compactors. Volvo has a hub in the Lingong factory which produces road rollers and pavers. The hub is managed by Volvo CE themselves, although they obtain the services and the employees from SDLG. (Million 2009) 


\subsubsection{Volvo CE Shanghai}

The Shanghai plant is located in the JinQiao Development zone in the east part of Shanghai; it is producing excavators and has about 250 employees. The plant has got two assembly lines; one is producing the EC55 and the second one is producing EC360, EC210, EC240, and EC290. The last three models mentioned have been produced since the start up, the EC55 was implemented in the production line in 2004 and in 2009 the EC360 was also added. The construction of a fabrication building started in 2006 and the year after it was taken into use. The factory has a capacity of producing 15 machines per day, in normal working hours. (Lu 2009) In the year 2008 the production reached 2126 units; out of them 1700 excavators and 426 compact excavators. The expected production for the year 2009 is 2442 units; 1800 excavators and 642 compact excavators. (Chen P., 2009)

\subsubsection{Shandong Lingong}

Shandong Lingong is situated in Linyi, Shandong province P.R China. The company was established in 1972, has a gross asset of 2600 million Yuan, and has over 2000 employees in total. SDLG are mainly producing Wheel Loaders, Backhoe Loaders, Hydraulic Excavators, and Road Rollers. In total SDLG are producing nearly one hundred different kinds of products, which distributes to approximately 170 independent dealers in China. SDLG also exports to several countries; for example Australia, Latin America, the Middle East, Africa, Russia, Mongolia, and South East Asia. The SDLG vision is to "Establish a famous brand, and make Lingong a centenary enterprise!", in order to strive against that vision they established an Industrial Park. (www.sdlg.cn, 2009) The total land area of the industrial facilities covers 660 000 square meters and it contains 12 assembly and fabrication workshops (sdlg internal). In 2006 Volvo invested in Lingong to create a JV with Volvo as majority shareholder. The company still has its own manufacturing of components, assembly line, and manages operations independent from Volvo.(Million 2009)

SDLG has been awarded two certificates and one license; the quality management system certificate ISO9001, "Export Products Quality License", and "Import/Export Enterprise Qualification Certificate”. (www.sdlg.cn, 2009)

\subsection{SKF}

SKF (Svenska Kullager Fabriken) was established in Gothenburg, Sweden 1907. The company have manufacturing sites in over 100 locations worldwide and 40000 employees. SKF Group is the global supplier of products, solutions, and services within rolling bearings, seals, mechatronics, services and lubrication systems. The company have six manufacturing units in China; in Dalian, Wafangdian, Beijing, Wuhu, Pinghu, and Shanghai. SKF have two service units and over 20 sales offices. The Head Office is located in Shanghai. SKF was, in 1998, the first bearing manufacturer to receive a global certification according to ISO 14001. SKF have a positive attitude to environmental work and are working active to continuously improve. (www.skf.com, 2009) 


\subsection{Sandvik}

The company was established in 1862 in Sandviken, Sweden, where the Head Quarter still are situated. The company has around 50000 employees worldwide and are represented in 130 countries. Sandvik is a global enterprise in the fields of material technology. Operations comprise the Tooling, Mining and Construction, and the Materials Technology business areas. The main focuses for the Tooling business area are tools and tooling systems for metalworking applications. Companies in the automotive and aerospace industries are the major customers for this area. Rock-working equipment and tools used in mining and civil engineering worldwide are specialties for the Mining and Construction area. The third business area, Materials Technology, is mainly developing products in stainless steel, special alloys and resistance heating materials. They are also producing process systems and the customers are found in most industrial segments. Sandvik can be found in six different places in China; Beijing, Shanghai, Wuxi, Qingdao, Zhenjiang, and Hong Kong. (www.sandvik.com, 2009) 


\section{Volvo wanted position and guidelines}

\subsection{Generally}

Volvos wanted position is based on fulfilling the mission and reach the vision set for the company. The wanted position is where the mission and vision converge.

To be able to fulfill the objectives it is important to understand the goals and the Volvo way of achieving them. Continual improvements are one of the watchwords, just as customer focus, open dialogue and company spirit. Regardless of work assignment or position every individual is able to change and improve performance. The company spirit means acting in the most suitable way for the company. An open, honest, and active communication is beneficial for both the company and the personnel. Leadership is also an important part when struggling to meet the spirit of the Volvo way. Leadership requires active communication and the leader must earn respect of the team. Quantify, Measure, and Deliver is keywords when proceeding from word to effective action. As soon as a decision has been taken the focus should be on the implementation process. The goals are to build a more successful and competitive company, whom is customer-focused and profitable. A company who the employees' can be proud of and which supports personal development. (Volvo internal, 2009)

"Number one in image and customer satisfaction.

Sustainable profitability above average.

Number one or two in size or superior growth rate."

- (Volvo internal, 2009)

\subsection{Production sites}

"Environmental requirements for production sites and other operating units within the Volvo Group", see Appendix 1. 


\section{Pilot study}

A pilot study was carried out in order to get the view of International companies' environmental work in China. Three Swedish companies were chosen; VCE, SKF, and Sandvik. General for the interviews was that questions were asked about how the companies work with EMS, both present and for the future. Also some study visits were done to get a general view of the companies, plants, and equipment.

Chosen interview persons at selected companies operating in China:

\section{Volvo Construction Equipment}

- Phil Chen -TQM Manager

- Yuluan Wang -Waste water coordinator

- JC Lu -Safety and Environment Manager

\section{SKF}

- Lewis Wu, EHS manager China

\section{Sandvik}

- Hans Kjelltorp, EHS manager Zhenjiang

\subsection{Volvo CE Shanghai}

The Volvo CE plant in Shanghai (VCEC) was founded in 2003. It produces excavators and has a production capacity of 15 units per day. The plant area is 65000 square meters and of that 10000 square meters consists of an Assembly building and 6230 square meters is a Fabrication building. Beside the plant a new office building for Volvo was recently built. It was completed in January 2009 and by the same time the staff moved in. The different parts of Volvo group; CE, Parts, Buses, VCIC ${ }^{1}$ (Volvo China Investment Co.), that had offices in separate places in Shanghai before are now situated in the same building. A showroom was built in the new office building to show the products, how they work, and to use for training purposes.

The plant has 255 employees; of whom 195 are working in the factory and 60 in the office. The allotment of male and female managers is comparatively equal; $42 \%$ female and $58 \%$ male managers. The proportion of different educations are nine masters degrees, five candidates to MBA, 41 bachelor's degrees, and 33 junior college degrees. The team working with environmental and safety issues consists of six Volvo employees, in addition five workers hired external to manage the cleaning and waste materials. (Chen P., 2009)

\footnotetext{
${ }^{1}$ VCIC includes Logistics, IT, 3P, and NAP (Non-Automotive Purchasing).
} 


\subsubsection{Environmental work}

The company is well aware of the importance of environmental work and takes the duties very seriously. The attitude to ISO 14001 is very positive at the plant and much effort is put into educating the employees, making improvements, and reviewing their work. VCEC followed from the beginning the Volvo group environmental policy. In 2005 concurrently as the preparation work for ISO implementation, VCEC developed and implemented a local plant policy; which is consistent of the Group policy and also customerized. One of the main reasons to develop a local plant policy was that the factory is more process oriented and wanted to integrate both environment and safety in the management system.

The Safety \& Environment (SE) Manager is responsible for the Environmental policy and the daily environmental activities. Responsible for coordinating the EMS is the Total Quality Management (TQM) Manager. The Management Representative's (MR) duties are to coordinate the internal audit, organize the management review of the EMS, to periodically review and update the environmental policy, and to assist the GM to set up annual environmental objectives. The management team are working with, and taking decision on environmental questions through group discussions. In all decisions four perspectives are taken into consideration; technical, financial, customer focus, and if current status comply with legal requests, and also if the legal request complies with the local governmental request and the group organization request. The management team consists of heads of department for all the ten departments: maintenance \& engineering, quality, material handling $(\mathrm{MH})$, manufacturing, SE, TQM, production planning (PP), human resource (HR), finance/IT, and purchasing. All the departments are key departments in questions concerning EA, laws, regulations, objectives, targets, programme(s), and also operational control. (Chen P., 2009) Other activities can be read in the Matrix in Appendix 2.

\subsubsection{VCEC Environment Management System Matrix}

The departments' allotments and responsibilities for different requirements. See Appendix 2.

\subsubsection{EMS/ISO 14001}

The factory got certified according to ISO 14001 in 2006. It was already certified with ISO 9001 in 2004 and OHSAS 18000 in 2005. The company worked with environmental issues, and followed the legal requests, even before the implementation of ISO 14001. (Chen P., 2009) According to the governmental requirements the company has to install their own water treatment plant from the start up (Lu 2009). There was though no waste classification, recycling, or energy saving program before, so much improvements were made when ISO 14001 was implemented. There is yearly both an external and internal audit. Every third year there is a complete audit made. This was latest made in March 2009. (Chen P., 2009)

\subsubsection{Implementation process}

In 2005 a management representative was nominated and the management team, including heads of different departments, was then organized by him. The head of departments, in the different fields, organized the 10 teams. The teams were then confirmed by the GM. 
The local environmental policy for the plant was set to contain;

- Comply legal requests

- Continuous improvements

- Prevention ideas

The ESC grade point system was adapted from ISO 14021-29 and was a useful tool in the identification process of environmental aspects. ESC stands for; Impact frequency to environment (E), Emission quantities (S), and Energy impact (C).

When the team, the time frame, and the plan were resolved; the training started with how to conduct initial environmental assessments. The environmental aspects had to be identified, prioritized, and controlled. Each team identified the EA regarding their field, with support from SE manager and MR. 200-300 aspects were found and 30 of them were estimated as significant aspects; key areas for the EMS to focus on. Material and information regarding the aspects were gathered. 13-15 documents and a list of chemicals use had to be provided to reach the legal requests. There are two different approaches on working with the aspects. The first approach is how to manage the aspects and how to control them. The second one is focusing on improvements. To decide what should be the objectives out of the significant aspects, four different areas had to be included; technical, financially, interest parties, and evaluation criteria for setting up the objectives. Four objectives were established. Working instructions has to be done for the remaining significant aspects. According to the final score of the ESC system the highest prioritized and therefore also the main aspects were;

- Emissions to air from the paint workshop

- Waste water from the paint workshop

- Potential risk of explosion by air engine station.

A plan of how to achieve the objectives, an environmental program, was done. A methodology, a timeframe, and responsibilities were elaborated, and approved by the GM. An environmental impact assessment (EIA) was carried out by an external environmental protection agency and a trial run was done. (Chen P., 2009)

\section{Local Environment Policy}

Care for the Environment is one the of core values of the Volvo Group.

We will ensure that all operations and products are leading edge on environmental care. To minimize our impact on the Environment, we rigorously control emissions and disposal of waste and use environmentally friendly manufacturing materials and processes whenever possible.

We are also committed to minimize the local environmental impact in our production process by reducing noise, fuel consumption and harmful emissions. (Volvo internal, 2009)

\subsubsection{ESC grade point system}

The ESC grade point system is a system to calculate the importance /how immediate they have to be dealt with and rank the EAs among themselves. 
The EA are analyzed and valued according to;

Impact frequency to environment (E) $\quad 0.1-1$

Emission quantities (S) $1-5$

Energy impact $(\mathrm{C})$. $1-100$

The three categories times each other gives a score which indicates the importance of the EA. Below 190 means that the level is ok and over 190 means that improvements have to be made. The ESC-score is first calculated without any improvements taken into consideration. The current status, with the management method is then comprised. A new calculation is made with the current status included to give the present score. This method shows how much the improvements do for the score and in other words the importance of the environmental work. (Chen P., 2009)

\subsubsection{Training communication}

To conduct a complete and durable training is it important that the communication get through to all levels of the company. Firstly it is important with fully support from the GM and secondly the basic knowledge to the employees.

Main dimensions of training before implementation;

1. Environmental awareness

2. Environmental Important Function (specific related to positions and areas)

3. Special Function (12 licenses signed by the government after external training)

A training plan was set up to make clear i.e. what kind of information has to be communicated and is related to environment, who have to know about what, and how often meetings are necessary. When the training plan was conducted the next step was implementation of training to make sure that the procedures are followed up. The implementation consisted of "planning and conducting of communication" and "planning and conducting of monitoring". The monitoring is divided into three different fields; the operational monitoring, legal compliance monitoring, and objective achievement monitoring. (Chen P., 2009)

\subsubsection{Environmental protection}

\section{Waste water treatment}

According to the governmental requirements the company has to install their own water treatment plant from the start up. One person is working fulltime with running the water treatment facility. There are samples taken on the treated water every day and the result is documented. This is mainly to check COD and oxygen in the water. (Lu 2009) To treat the water polyacrylamid and aluminium polyklorid is used. (Wang Y., 2009)

\section{Emissions to air}

The equipment to check air emissions is a large investment and to buy the service external is also very expensive. The testing of air emissions are therefore done one to two times per year of an external company. (Wang Y., 2009) 


\section{Solid waste}

The solid waste is collected and stored in a special area in the plant and then taken care of by the waste handling company, XinJinQiao. The area is well structured and one person is working fulltime and has the overall responsibility for the waste handling. Paper, plastic, and hazardous waste are stored indoor and are later sold to the waste handling company. (Lu 2009)

\section{Hazardous waste}

The hazardous waste is stored in special part of the area for solid waste. It is located indoors and is taken care of the waste handling company, XinJinQiao. (Wang Y., 2009)

\section{Noise}

The noise level inside and outside is tested once or twice per year, at the same time as the air quality. (Lu 2009)

\subsubsection{Difficulties and benefits}

According to the interviewed Volvo employees there are several benefits of implementing an environmental management system. The most important, and also what is the base for successful environmental activities and continuous improvements, is the thinking from a prevention perspective and a systematic approach. The VCEC goal for accidents are always zero and the reducement of both work related risks and environmental risks is a large benefit from working with an EMS. To improve the environmental awareness of employees is a benefit both for the company but also for the employees daily life. The awareness of constant improvements is important and a systematic approach is a helpful tool to i.e. annually lower the emissions and in preventing from using prohibited materials in the black- and greylist, which is a classification of materials used in the VCE production. The preventing of the use of prohibited materials is a benefit both from an environmental perspective and for the working climate. To reduce the emissions also bring forth a better relationship with the neighboring environment. The resource utilization is of great concern to the company. Further examples of benefits for the environment and from an economical perspective, are that VCEC currently is using metal wrack packing of machines, instead of wood, and the water consumption have also decreased. (Chen P., 2009) The work has also generated reduced costs of domestic water supply and reduced use of energy. (Lu 2009)

One of the major problems for international companies is to meet the legal request in combination with their own companies' environmental policy. This does not seem like a large problem but could be relatively time consuming before solved. The issue is to localize the environmental policy and requests of the company to meet the legal requirements. The attitude is also a problem when trying to combine different cultures. The top management support is important when new projects are launched, people of different background and working position value things differently. The persons that will represent a base for the daily work and therefore are a just as important part, is the employees on the shop floor. That their attitude towards environmental work is positive and that they take an active interest is important. To succeed in an ISO certification not only knowledge is necessary but attitude. To use a systematical approach is time saving. To coordinate different teams, use monitoring programs and perform training of the employees are all thing that results in avoiding unnecessary difficulties. To stick to commitment stated in the policy is a problem, onsite performances, facilities, and equipment represent investments and to stick to the progress are all possible problems. (Chen P., 2009) 


\section{SKF China}

SKF have five manufacturing units in Shanghai; they are SKF (Shanghai) Bearings Co., Ltd, ABBA Hitech (Shanghai) Co., Ltd, SKF (Shanghai) Automotive Technologies Co., Ltd., SKF Automotive Bearings Co., Ltd, and SKF Industrial Service (Shanghai) Co., Ltd. In total they have 11 manufacturing facilities in mainland China, they are all certified, by DNV, according to ISO 14001 and OHSAS 18001. The certification combines both these two standards. SKF are also certified, by Lloyds, according to ISO 9001 since 1997, but separate from the environmental and safety certification. Every unit has an EHS coordinator; a full time job or a part time job with priority for EHS, and they have one EHS Country coordinator overall responsible for the China market. (Wu 2009)

\subsubsection{Environmental work}

Before the implementation of ISO 14001 there were huge gaps between the existing environmental work and what was expected of the company. This is one of the largest benefits with implementing an EMS. The employees did not know enough about ISO 14001 and OHSAS 18001 and the awareness of i.e. safety behavior for operators was far beyond expected. There was also no system assessment of regulation compliance. One of the focuses is always the permits, because there should be no major non compliance towards regulation compliance. That is why all the related permits at each units has to be finished, and the challenge is that receiving permits is not depending on the struggling, more likely up to local office's will and efficiency; this is a fact that SKF has been meeting and cannot avoid. The permits are including; environmental assessment report and approval, occupation diseases assessment report \& approval, drain permits, landscaping, fire protect, building quality etc. The most important to effectively run an EMS is to have support from the top management. It is an SKF minimize requirement that risks have to be avoided/ reduced. It is also important to create company culture; to improve the communication, housekeeping, and safety. SKF are working according to the integrated SKF Environmental, Health and Safety Management System which have four different levels; at the top a Group Environmental, Health and Safety Policy, below that Group EMS Manual with procedures (Eb). The National supplements to Eb are called Ec and at the bottom the Local supplements to Eb which is called Ed.

The Steering Group of EHS Committee consists of the GM and managers, seven representatives from different functional departments; EHS representative, production manager, engineering manager, material flow, finance manager, HR manager, and quality manager. The working group of the EHS Committee includes the EHS management representative, an ESH coordinator, and eleven employee representatives from different functional areas. During the meetings a minimum of eight employee representatives have to be present. (Wu 2009)

\subsubsection{EMS/ISO 14001}

SKF China ran ISO 14001 certificate in 1998 and they started OHSAS 18001 certificate in 2005. ISO 9001 was in progress in 1997. The main reasons applying for the certification was that it became mandatory by SKF Group. Other reasons where that it is requested by customer, for the systematical approach, and to avoid potential risk. All the 128 units around the world are certified as a group. (Wu 2009) 


\subsubsection{Implementation process}

SKF are at present running an EMS and it was set up according to the PDCA (plan-do-checkact) cycle. During the implementation process the starting point was to make the responsibilities clear and stated, i.e. the Steering committee and Implementation team. Focus for the training was after that the EHS awareness arranged for all employees and the legal demanding course for all managers. To introduce ISO 14001 and OHSAS 18001, and the internal auditor training for these standards, was also included in the training. An EMS was thereafter set up. The employees were involved in the work with environmental aspects, hazardous identification \& risk assessment, and the regulation compliance. An internal audit was carried out, followed by a performance review and a Group audit. Correctives and prevention work were made and finally an audit done by DNV was performed.

An SKF Group audit is held every second year and it was latest carried out in the beginning of April 2009. An internal audit is made every year, following the audits are always correcting and action plans towards the finding raised. The certification body, which in SKF Chinas case is DNV, are performing an audit every third year. (Wu 2009)

\section{Environmental Policy}

The Group's overall objective is to attain long-term and sustained profitability. The main task related to this objective is to develop, produce and market products and services that satisfy the needs of our customers and at the same time are safe for their intended use. They should be efficient in their use of energy, protective of the environment, and be recyclable or safely disposable. (www.skf.com, 2009)

"This policy describes SKF's commitment to health and safety as well as the internal and external environment. Current laws and regulations, and commitments to which SKF subscribes, are to be considered as minimum requirements. All SKF companies shall maintain long-term environmental, health and safety (EHS) plans which shall be continually adapted to developments, new discoveries, and experiences related to EHS. Operations shall be conducted in a manner that protects the health of our employees, protects the environment and conserves energy and natural resources. EHS performance shall be continually improved. EHS effects shall be taken into account when business decisions are made. SKF companies shall strive towards a constructive communication with their local communities as well as the EHS authorities concerned. Suppliers and sub-contractors shall be required to adopt the principles of this policy. SKF companies shall provide safe and attractive workplaces for all employees and shall ensure that the employees are sufficiently educated and trained to apply this policy in their daily work.

Regular assessments of compliance with this policy shall be conducted by all SKF companies. EHS performance shall be measured and reported regularly to shareholders, employees and the public." (www.skf.com, 2009) 


\subsubsection{Environmental Aspects system}

An environmental aspect system is used at SKF China to find the EA and their significance. The EA shall be listed in a special form, out of which the significance will be calculated. A review shall, in some cases, be carried out by the Environmental Coordinator depending on process changing, change work, adding new machines etc.

How much impact the aspects contribute to shall be analyzed and valued according to the ratings; $1=$ small impact, $2=$ medium impact, $3=$ large impact, $4=$ vital importance. The rating will be applied to four categories according to;

Probability (the probability of occurrence of impact);

$1=$ low, 4 = high

Duration (how long the impact lasts);

$1=$ short, 4 = long

Severity (extent of damage or harm to the environment); $\quad 1=$ small, $4=$ vital

Liability (the potential for legal or regulatory noncompliance); $1=$ low, $4=$ high

The numerical ratings shall be added together to show the significance of the aspects.

\section{Significance}

Vital importance and impact

High priority and impact

Medium priority and impact

Low priority and impact

\section{Total score}

13-16

$9-12$

$5-8$

4

Taken into consideration are also the environmental aspects' effect on legal compliance, business concern, and public image;

Regulated:

Business concern:

Public Image:
Yes - the aspect is regulated by legislation

No - the aspect is not regulated by legislation

Yes - finance is available to reduce the impact

No - finance is not available

Yes - the aspect affects the reputation of the company

No - the aspect does not affect the reputation of the company

Considered significant should be all the EA that are regulated by legislation or rated Vital importance or High priority be. If also the Business concern is "Yes" or the Public image is "Yes" the EA should be included in the Objectives and Targets. (SKF internal, 2009)

\subsubsection{Environmental protection}

SKF China has today a well working communication, due to daily activities. The company has a monitoring and reporting system which can be further read about on www.skfcompass.com, it informs how the trend goes. An agreement has been reached between operators and management for the existing problems and those of improving.

In the year 2010 SKF have planned to combine the ISO 9001 certification with the one for ISO 14001 and OHSAS 18001. This will be even more time and money saving. (Wu 2009) 


\subsubsection{Difficulties and benefits}

There are a lot of benefits with implementing and running an EMS. From experience, SKF mean that possible risks are avoided/ reduced, particularly in a long-term perspective. The companies' image is strongly reinforced to customers and community, it force to create companies' environmental care, and employees care culture. To run an EMS will improve the awareness of the employees which is a base to a successful work. The systematical approach to zero accidents control at site is highly prioritized at SKF and has reduced the recordable accident rate significantly. A well working EMS will contribute to energy efficiency projects, water saving, and increase material recycling. It will also be a helping tool of sharing achievements and replication successfully at sites. The audit is performed every third instead of every second year. With a group contract the total costs for certification processes will be reduced, due to that the documentation does not have to be checked during every certification, only the plants. Generally the certification process went well for SKF. One problem was though that a pre-inspection, at the two JV, showed that too many correctives were asked for and the unit people worried about to complete it within the limited period of one year. According to the EHS manager at SKF assuming difficulties for other companies could be that the current status is far away from what is expected. Other problems could be poor awareness for the site workers, resources to drive the implementation, and too many other priorities for site management. (Wu 2009) 


\subsection{Sandvik Zhenjiang}

Sandvik Materials Technology (SMT) consists of six product areas: Tube, Strip, Wire, Kanthal, Process Systems, and Sandvik MedTech. SMT has a factory in Zhenjiang, China. It is a recently inaugurated factory and test runs are currently in progress. The factory will produce stainless steel tubes for i.e. the chemical industry and the shipbuilding industry, and have around 100 employees. (Kjelltorp 2009)

\subsubsection{Environmental work}

The plant has recently been internal audited, of a team from the Headquarter in Sweden, to find possible remaining weaknesses. The phase that the Zhenjiang plant at present is facing means to prepare for different Governmental appraisals that will be carried out when the production has started. The issues include making sure that the factory reaches the legal requirement. Sandvik Materials Technology has a Multisite Environmental Management System, an Environment Health Safety (EHS) system, which means that all 35 units worldwide have adapted the same way of working. The Zhenjiang plant will continue working with improvements on a local basis and relatively soon affiliate to the global environmental system. A third party audit will then be carried out to evaluate if Zhenjiang could be included in the Multisite ISO certification. The plan is to be certified as latest the year 2010 .

Sandvik are working according to a global environmental policy. The global environmental goals are set by the Headquarter in Sweden. The goals contain among others $\mathrm{CO}_{2}$-emissions, water consumption, oil consumption, and use of energy. Each factory is then responsible for setting local goals within the global once. In addition to the global once each factory could also have own local environmental goals. (Kjelltorp 2009)

\section{Environmental Policy}

Environment, health and safety issues are integral parts of Sandvik's total operations and the company achieves continual improvement in these areas through management by objectives. Sandvik believes that the greatest effect is achieved through preventive actions.

The company follows an approach that results in long-term sustainable development in its operations. Consequently, Sandvik strives for high efficiency in the use of energy and natural resources, promote systems for recycling and recovery of materials and work to prevent pollution and any work-related illness and injury.

Sandvik strives to provide a healthy and safe work environment that stimulates employees to perform effectively, to assume responsibility and to continue to develop towards their personal and professional goals.

Sandvik complies with or exceeds applicable environmental, health and safety, legal and other requirements. The company believes that common and effective environment, health and safety requirements and standards should be established at an international level. (www.sandvik.com, 2009) 


\subsubsection{EMS/ISO 14001}

The Sandvik plants around the world are ISO 14001-certified together through a multisite certification. The Zhenjiang plant is still not a part of the process, but the plan is to be certified as latest the year 2010. (Kjelltorp 2009)

\subsubsection{Implementation process}

The implementation process is not done since the plant is still in the initial phase. (Kjelltorp 2009)

\subsubsection{Environmental Aspects}

Sandvik has Global identified its largest environmental aspects and they are set to be: energy consumption -electricity and fossil fuel, raw material consumption -metals, use of fresh water, carbon dioxide emissions, and waste. Out of the EA the three group environmental goals were set;

- Reduction of energy and raw materials consumption

- Reduction of emissions to air and water

- Increase in materials recycling, both internally in the manufacturing processes and externally by recycling of our products

(www.sandvik.com, 2009)

\subsubsection{Environmental protection}

The factory has gauges inaugurated in several discharge sources. All Sandvik plants have a responsibility to twice a year report a compilation of the previous half year's environmental performance. The Zhenjiang plant will be ISO 9001 certified related to the production start up. ISO 9001 certification is a customer demand. The global EHS system that will later be affiliated to is also including OHSAS 18001. (Kjelltorp 2009)

\subsubsection{Difficulties and benefits}

A well structured environmental work and the demand of continuous improvements are two of the largest benefits with the implementation. To have employees that really know the Chinese Environmental regulation, good communication through all levels, and of course top management support is good combination for a sustainable environmental work. It is really important that a lot of effort is put into the work with interpreting the governmental laws and regulation. Local support is of great concern in the work, even though top management support of course is very important. One problem Sandvik has faced is that different interpretations of the local requirements have been found. The consultants have their interpretation and the EHS engineer has a different one. A third interpretation was done by environmental specialists in Sweden, out of a translated version of the Chinese regulations.

Several of the employees from Zhenjiang have been to Sweden for training. Many of them came back with the opinion that Sweden has so clean air. They are talking about that Sweden must have very little emissions and good environmental work in companies. QA\&EHS Manager, Hans Kjellstorp, at Sandvik Zhenjiang is hoping that these experiences could be transferred into practical work to improve the environmental standard in the area. (Kjelltorp 2009) 


\subsection{VCE Hub in Linyi, Shandong Lingong}

The VCE Hub in Linyi is situated in one of the workshops in the SDLG factory. The Hub works independently with a Volvo management team. It produces road rollers and pavers with Volvo brand, but they obtain the services and work of employees from SDLG. (Million 2009)

This chapter is based on reflections from interviews and factory tours with Jianping Wang, Chief Safety \& Environment, at Shandong Lingong Construction Machinery CO. Due to i.e. lack of important documents it cannot be seen as a comprehensive analysis. It is reflections based upon the information gathered during the time spent in Linyi.

\subsubsection{Environmental Management System}

\section{General requirements, policy, and strategies}

SDLG have an ongoing work with environmental questions but the general impression is that they still do not have a working EMS system. Their main target is to reach the governmental requirements, which they do. The environmental thinking and the understanding of its importance in all levels of the company is though not comparable to the ISO 14001 standard or Volvo Environmental Policy.

\section{Objectives, targets, and legal requirements}

SDLG are well aware of, and have access to, the legal requirements. They do not have a system for environmental checking, it is done when it is needed, and not documented. They do not have objectives and targets written down. Still there is no implementation program for the aspects; the problems are attended to when they occur. SDLG have established EA but they have no proper procedure for how to establish and how to evaluate the aspects. They have different control points when implementing a new project or process.

\section{Structure, responsibility, and training}

The deputy of each department are responsible for the environmental work, in the workshops the person is also responsible for quality and safety. Documentation promises that each department will follow the procedures stated in the established and documented emergency plan; "Emergency Rescue Plan of Shandong Lingong Construction Machinery Co. Ltd". The document is approved by the GM and contains instructions to protect the employees' life-safety, to reduce property loss, and to rapidly take actions in case of emergency. An emergency team is established and they will operate in case of emergency.

Four people are working with environmental and safety fulltime at SDLG. One person, Chief Safety and Environment, is overall responsible for the work. The three others do not have specific targets but share the work in between them.

\section{Operational control and emergency preparedness}

The Waste Water Treatment (WWT) plant has working instructions established and the monitoring of $\mathrm{pH}$, time of letting out the treated water, and the sludge, is documented. The water is normally let out twice a day and the sludge once a day. The monitoring of air emissions are made by the government and not at regular intervals, the same procedure concerning the noise level. The last check was in February 2007. 
The waste is collected in bins around the factory. The waste is later sorted, into different fractions, at the Waste Yard (WY). Metal, paper, and plastic are sold and hazardous waste is taken care of by a waste handling company. One person is in charge of the WY and several people work with collecting and sorting the waste.

SDLG have two kind of working permits which are compulsory; both a regular work procedure and also a hot work procedure. Approval is needed before hot work starts. An emergency plan is established and documented; "Emergency Rescue Plan of Shandong Lingong Construction Machinery Co. Ltd". The document is approved by the GM and contains instructions to protect the employees life-safety, to reduce property loss, and to rapidly take actions in case of emergency. All equipment has an instruction of how to be checked and it is done every day. Each employee is also responsible for checking their own equipment. The fire extinguishers are checked every month and a fire drill is carried out yearly. An emergency team is established and they will operate in case of emergency.

\subsubsection{Environmental Aspects}

Below empirical information is gathered carrying out interviews as well as factory tours with Jianping Wang, Chief Safety \& Environment, at Shandong Lingong Construction Machinery CO.

\section{Air emissions}

The monitoring of air emissions are made by the government and not at regular intervals.

\section{Water emissions}

SDLG gets a monthly report concerning the water consumption; its amount includes both the production and daily work. The wastewater is treated with natriumhydroxide $(\mathrm{NaOH})$ to adjust $\mathrm{pH}$, the water is kept in two underground pools. It takes four hours to accumulate the sludge in the waste water after that the slugged if left to dry. The water is antirust treated by passing a filter before handed over to a waste water treatment company for further methods of treatment.

\section{Chemicals}

SDLG complies with the governmental requirements for chemical products. Chemicals are stored in a room for that purpose, only a few people have access to the chemical warehouse. No Safety Data Sheets (SDS) is available close to the working place, but one measure the potential risks of the paint are accessible outside the painting line.

\section{Waste}

The waste is collected in bins; there are both recyclable and non-recyclable waste bins in the Hub. The waste is sorted in the WY into different fractions; metal, paper, plastic, regular, and hazardous waste. One person is in charge of the WY and several people work with collecting and sorting the waste. The WY is an area with different divisions for different sorts of waste. Walls separate the divisions from each other. The area has a roof but it is still not indoors.

\section{Noise, odour, dust -nuisance to neighbors}

The noise level is tested in four places, one meter outside the plant; on the north, west, south, and east side. The testing is carried out twice in each place; both during the day and the night. The indoor noise level is checked yearly, however the outdoor level is not regularly checked. SDLG reach the governmental standard for noise level. 


\section{Analysis and discussion}

In this study the aim was to investigate and analyze how the VCE Hub at Shandong Lingong can evolve their environmental work to reach Volvo standard. In order to spread light on that question one also has to understand how international companies can influence and teach Chinese companies about environmental guidelines. Therefore, in a broader perspective, this study also aimed to investigate what international companies in China should take into consideration in their environmental work. The work was carried out by answering the following research questions:

1. In which way or ways can the VCE Hub at Shandong Lingong evolve their environmental work to reach Volvo standard?

2. What should international companies take into consideration in their environmental work when establishing on the Chinese market, and why?

\section{In which way or ways can the VCE Hub at Shandong Lingong evolve their environmental work to reach Volvo standard?}

VCE's JV relationship with SDLG provides both benefits and challenges. In terms of "controlling" SDLG the relationship tend to be more of a challenging kind. Especially when it comes to way or ways that the VCE Hub can evolve SDLG's environmental work to reach Volvo standard. VCE cannot manoeuvre SDLG the way that they wish since SDLG, no matter of the percentage of VCE ownership, can still run their work the way they prefer until 2012. From my point of view the only way to steer or control SDLG is to convince them the importance of environmental issues by establishing a new way of thinking. To only implement procedures, and not the way of thinking, will probably not create a sustainable relation. If SDLG can understand all the benefits of working active with an environmental management system, and not just the costs, it is a big step forward. To create this relation between VCE and SDLG and implement an EMS will probably take time due to cultural differences, this time is however well invested time. To handle the challenge with patience and by establish a new way of thinking where a recognized suggestion amongst people interviewed.

SDLG is a large company and to be able to work with environmental questions in a proactive way, the organization has to be restructured. A new management system, built in a way that Volvo environmental requirements are fulfilled, will be needed the year 2012 .

VCE is currently in a changing phase where they restructure the environmental-, safety-, health-, and quality-work. The former TQM, EHS, and Volvo Production System (VPS) will now together form the new Quality Environment Safety (QES). From my perspective it is not preferable to wait three years with the preparation for a Volvo EMS and an ISO certification; it is obvious that SDLG then will be three years behind all other plants in 2012. A direct implementation for the Hub is recommended according to me. Preferable is that SDLG during the process will have total insight into the affairs of the implementation. The daily work should be combined with new activities; step by step, project by project. The implementation and to run an EMS evidently costs money, I however think that the investment in the long run will create great return on invested money. I believe that if the benefits of the work are highlighted and communicated within all levels in the organization, it is easier to realize the return on invested money. If this way of thinking is implemented it is a big step in the right direction. SDLG have to feel that they make difference and that their opinion also matters. Of course the companies have to create revenue, but as soon as they do they should take their environmental 
responsibility. How large investments that are done depend on the size of company and their profit, but continuous improvements should be done. The companies have a responsibility to balance profit against their environmental issues, and this responsibilities will be even more significant in future considering the environmental debate that will affect all competitive companies striving to win market shares. It is also preferable that as many documents as possible is translated into both Chinese and English, to avoid misconceptions, to facilitate the communication through all levels and the understanding between cultures.

As mentioned before in the chapter 3.1 it is a quite complicated process to get ISO-certified in China. To apply for a certification an organisation must have had an EMS established and operated for a minimum of three months. The organisation also has to comply with national and local environmental laws, regulations, and requirements. It is a lot of work to fulfil all this and to continue to make improvements. Which is why it is so important to have a well structured work with clarified routines and both employees and a management team that are fully committed to the work. The management team should be consisting of representatives from all different departments, this to generate a transparent work and establish the strategy organization wide. The cornerstone when working with EMS and ISO certification is the environmental aspects, according to the interviewed SGS audit team. A management team with all departments represented, clear duties, and a dialog with the GM is a good base for a continuous improving system. The organisations themselves decide the certification bodies and consulting institution filed, which shows that there is space for the company to influence and build a system that suits their organisation.

After this study one asks the question; how should the Hub deal with the ISO 14001 certification process? There are three different alternatives according to me:

1. The first option is to certify only the Hub itself and not include SDLG in that process. A certification process is a quite complicated process; many documents have to be prepared and working structure stated. To do that for such a small unit is both money and time consuming. The Hub will be independent and not affected by other plants, on the other hand it cannot make use of the successful experience of VCEC and it cannot benefit from SDLG. It has to start from the beginning which means higher costs in double sense; both since they have to start the process from the beginning and since it is a small scale certification which means no chance to get a better prize thanks to quantity. Another negative side is the dealing with authorities; experiences have shown that sometime it becomes more complicated when the process is considering an International company. Either of the other alternatives makes this part less complicated; VCEC is already certified and SDLG is a domestic company. Below bullets reveal pros and cons with certify only the Hub itself and not include SDLG in that process:

$\begin{array}{ll}- & \text { Complicated process } \\ - & \text { Challenging for international companies } \\ - & \text { Time- and money consuming } \\ - & \text { Start from the beginning } \\ + & \text { Work independently }\end{array}$


2. The second alternative is to certify the Hub in combination with the VCEC in Shanghai, a so called "multi site certificate." This would be a way of getting the Hub certified even if SDLG would postpone their certification process or if they lack in ability to pass or keep the certification. This alternative would be cost effective though it is not as expensive to certify two parts together as doing it separately. The two units can share the information and work between each other. A risk can however be that a failure of one plant would affect the other one too. From the Hub's perspective it means that they could have a standardized process with VCEC and make use of that they are already successfully certified. To run the two plants together under the same certifications though means that they have to have a good coherence and collaborate on a daily base. Someone have to have the final responsibility for the collaboration. Another positive part is that the brand image will be kept, this by showing customers and suppliers that the policies and procedures are reaching Volvo standard. The certification body will just check one plant each time during their annual surveillance, which also makes the procedure less time-consuming. Other companies that were interviewed are successfully using multi site certificates for their whole organizations. It forces all plants to always reach the goals, since it otherwise will affect the whole group. Below bullets reveal pros and cons with certifying the Hub in combination with the VCEC in Shanghai, a so called "multi site certificate:"

$\begin{array}{ll}- & \text { If one plant fail all the other does too } \\ - & \text { Person responsible for the cooperation needed } \\ -/+ & \text { Constant collaboration needed } \\ + & \text { Cost effective } \\ + & \text { Share information and tasks } \\ + & \text { Companies brand value retains } \\ + & \text { Less time consuming } \\ + & \text { Demands that all parts of the organization contribute to the goal }\end{array}$

3. The third alternative is that the Hub will apply for the certification together with SDLG. Their plan is to finish the preparatory work during this year, 2009, and get the certification during 2010. In this alternative it has to be taken into consideration that SDLG may not be certified or able to keep the certificate, and then VCE will have been running business in the Hub for quite a while without having a certificate. This could mean lack of confidence from the customers and also affect the brand image negative. Then a new proposal will have to be presented for the forthcoming work. The two companies in this JV have fairly different ways of working and different priorities. It will be less work for the Hub separately, this since it is only a small part of the SDLG plant, and they can use each other's knowledge. The certification could also be seen as easier in terms of location since the two companies are situated in the same plant. A negative factor is that the standardized process within VCE will presumably not be used. The brand image could also be damaged since the customers know from the beginning that the two companies stand for different values and quality. Below bullets reveal pros and cons with the Hub applying for the certification together with SDLG: 


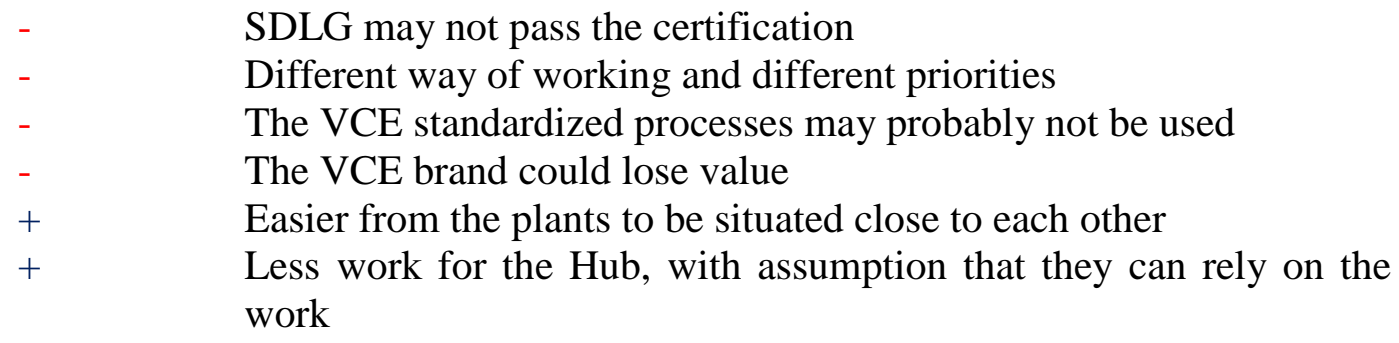

How long a VCE plant can wait before being certified is, outgoing from above discussion, a question depending on many different factors. All plants should be certified according to ISO 14001 and have a running EMS. A JV with SDLG was founded in the year 2006 and has still not resulted in a solution. A solution has to be taken about whether the focus should be to have an EMS and to get an ISO certification directly or if it is more favorable to wait.

\section{What should international companies take into consideration in their environmental work when establishing on the Chinese market, and why?}

The Chinese central government has realized that something has to be done about the environmental situation in the country; this has result in a set of new regulations and requirements for both national and international companies. However, these decisions are taken by the government and are, according to the interviewed persons, not rooted in the broad opinion, resulting in lack respect and authority among the Chinese people for the regulations. Samantha Rens highlight another problem that, from my perspective, have affected above situation. The problem concerns trust as she disclose that money invested by the government in environmental protection projects are easily "lost on the way", when passing different officials.

The interviewed people agreed on the vital environmental duty international companies have in China as they disclose that international companies must obey all the rules and show a good example, both for the international community but also for the Chinese companies. The international companies must set a good example that domestic companies hopefully will follow in their environmental work. Bleuenn Carre added the importance of transparency and respect of individuals. Samantha Rens believe that the more international companies and foreigners who come to China, the more China and Chinese people will become open to the world and realize their environmental responsibilities. This of course goes hand in hand as both parties mutually gain from it.

Bleuenn Carre describes the international values of team working that has been implemented in here company since her boss been working in Japan for a long time. She also pointed out that Chinese companies probably not will adapt solely to international companies' strategies but rather adapt some parts and outgoing from that form their own strategies. Jack Chen mentioned that international companies usually work more active to follow the law than domestic companies do. One reason could be that Chinese companies often have fewer resources available for environmental work. This makes it an even larger issue for the International companies to show the importance and to hopefully get the domestic companies to follow as much as they can. 
Aurore Nudin has a good point according to me, when she is talking about that not long ago international companies was far from being environmental role models. It was only quite recently that this changed. The change was driven by the fact that it has more or less become a completive edge to act and think with greater concern for the environment. Also the pressure of the society has increased. And to take environmental issues into consideration is an absolute necessity nowadays, according to Samantha Rens, Idrabel Environmental Biotechnology, and many with her. The companies' image is strongly reinforced to customers and community, it force to create companies' environmental care, and employees care culture, according to the interviews made. To learn from each other, giving and taking, makes people better at cooperating and communicating. The difficulties that an international company will meet can be reduced by knowing the regulations and requirements as well as the Chinese culture. Therefore good relations and the presence of knowledgeable Chinese employees are two very important rules in building a successful business in China. Different interpretations of the local requirements can be a problem for international companies according to Hans Kjellstorp, Sandvik. The consultants have their interpretation, the EHS engineer has a different one, and a third interpretation could be done by environmental specialists at the HQ out of a translated version of the Chinese regulations. This is one of the main difficulties, the Chinese system is complicated and to know it quite well is a condition to succeed.

The general impression among the interviewed is evidently that the international companies can affect China in a positive way but is then the regulations and requirements for building new plants enough for a sustainable development? Of course not is the gathered answer. The definition of sustainable development is a question of itself. I believe it is a question of definition. According to Aurore Naudin it means no adverse effects and no natural depletion. She also thinks that sustainable development still is on an experimentation stage. This can, according to me, be explained by the fact that China is a huge country and the culture of sustainable development has to be deeply rooted. -Lots of research, experiment, political will as well as society awareness are needed to adapt and implement sustainable development in China in a genuine sustainable way.

Responsibility is for some people a very positive word but for many people is it instead "scary". The society talks a lot about our responsibility for the Earth and that we have to take the environmental work seriously. I totally agree with that but people are different in different countries and one method and way of working is neither possible nor efficient in two different places. I agree with Aurore when talking about "environmental and human", rather than responsibility. In China responsibility is not the right word to use, the key is to make people understand how important their own daily contribution is. It is also important for people to understand the importance of companies that show they take their environmental duties seriously. Knowledge-, technical- and attitude training is the key to success in this case. If you are introduced to a new way of thinking or model, the best way to learn how to use it is to actively work with it and come up with solutions based on the new model, i.e., "learning by doing". A lot of issues may seem completely natural to international companies but years of influence and cultural differences have to be taken into consideration. It is completely normal that people do not take own initiatives, because they have been taught since childhood to respect the hierarchy and if you do more than you have been told you can also be blamed for it.

Many argue that one of the best and fastest ways of speeding up the environmental awareness in China is to promote both international and domestic companies to implement an EMS. Just as all investments an EMS is initially quite costly, demanding both time and resources. However, an EMS investment has to be seen in a long-term perspective, though initial results 
can be seen quite fast. Implementing an EMS face many challenges and a common problem in different layers of the Chinese society is the presence of complicated procedures and hierarchal chains. VCE has for example outsourced the painting to SDLG, whom in turn has hired contractors to do the job. A company has the duty to manage the painting procedure, though with SDLG's equipment and in their factory. This method could be money saving and effective with a well structured and transparent organization and an eye kept on the hired company. It could also be an expensive deal if the outcome is less good quality, neglecting of equipment, and bad housekeeping. The hierarchy is another issue related to the topic about complicated procedures and chains. Or as Hans Kjelltorp, Sandvik, explains it - communication through all levels is an important part of a well working EMS.

It is not sustainable to only take the current situation into consideration when planning new projects and taking decisions. It is important to always be one step ahead of your competitors in business, which most companies are completely aware of. That it is important to work proactive and not reactive in all questions is though not always clear in domestic companies in China according to the pilot study. Problems are quite often dealt with reactively and finding the source to the problem is often not investigated. To work proactive, clarify what could happen in different situations, and what measures that should be taken are a sustainable way of working and an essential way of thinking. If an accident will occur the costs for stopping the production will be very high. The probability that the accident will occur could be limited using simple means; such as working instructions and training for the employees' awareness. This is aspects that SKF really think is important, according to Lewis Wu. Also Phil Chen reveals that training is a key to success. Different cultures can learn a lot from each other and the same goes for different plants. As for example, all the interviewed companies agreed on that employees' awareness is a key to a successful EMS. One company sent employees abroad to get training and to be able to implement and convince their co-workers. The others agree that the best way of fully understand and dare to take own initiatives is to practice in reality.

To sum up the questions regarding what international companies should take into consideration in their environmental work when establishing on the Chinese market, I would like to point on the words open-mindedness and patience. People all around the globe think differently and what is right or wrong is nothing to speculate in. We wishes to implement our way of thinking into a country that has seen things from a totally different perspective for years and years. Equally often we want them to change attitude and to adapt our way of working. The most important is then to show the benefits and exchange experiences. We have a lot to learn from each other, if an international company is to be successful in China they need to understand the Chinese way of working. Chinese companies can learn the way of making their production and systems more efficient, from international companies. In contrast no international company will succeed without understanding the Chinese system and culture. In other words to learn from each other is very important. It is also extremely important that international companies are well prepared and knowledgeable before signing the contract. International companies can very well affect domestic companies in China with their way of working and the western way of thinking. JVs can be a perfect match if both companies are ready to change and take advice from another culture. To be open-minded and to have patience is of crucial importance when starting business in China. To show new opportunities, possible improvements, and the benefits of them is also important according to me. 


\section{Conclusion}

In which way or ways can the VCE Hub at Shandong Lingong evolve their environmental work to reach Volvo standard?

- VCE's JV relationship with SDLG provides both benefits and challenges. A big challenge for VCE is that they cannot manoeuvre SDLG the way that they wish since SDLG, no matter of the percentage of VCE ownership, can still run their work the way they prefer until 2012.

- The best way to steer or control SDLG is to convince them the importance of environmental issues by establishing a new way of thinking. If SDLG can understand all the benefits of working active with an environmental management system, and not just the costs, it is a big step forward. To create this relation between VCE and SDLG and to implement an EMS will probably take time due to cultural differences.

- SDLG is a large company and to be able to work with environmental questions in a proactive way, the organization has to be restructured. A new management system, built in a way so that Volvo environmental requirements are fulfilled, will be needed.

- It is not preferable for SDLG to wait three years with the preparation for a Volvo EMS and an ISO certification; it is obvious that SDLG then will be three years behind all other plants in 2012.

- A direct implementation for the Hub is recommended. Preferable is that SDLG during the process will have total insight into the affairs of the implementation. The daily work should be combined with new activities; step by step, project by project.

- Necessary is that the benefits with an EMS implementation, in SDLG, are highlighted and communicated within all levels in the organization.

- It is preferable that as many documents as possible is translated into both Chinese and English, to avoid misconceptions, to facilitate the communication through all levels and the understanding between cultures.

- It is exceptionally important to have a well structured work with clarified routines and both employees and a management team that are fully committed to the work. The management team should be consisting of representatives from all different departments, this to generate a transparent work and establish the strategy organization wide. A management team with all departments represented, clear duties, and a dialog with the GM is a good base for a continuous improving system. The organisations themselves decide the certification bodies and consulting institution filed, which shows that there is space for the company to influence and build a system that suits their organisation. 
- There are three different alternatives for how the Hub should deal with the ISO 14001 certification process:

1. The first option is to certify only the Hub itself and not include SDLG in that process. This alternative provides following pros and cons:

$\begin{array}{ll}- & \text { Complicated process } \\ - & \text { Harder for international companies } \\ - & \text { Time- and money consuming } \\ - & \text { Start from the beginning } \\ + & \text { Work independently }\end{array}$

2. The second alternative is to certify the Hub in combination with the VCEC in Shanghai, a so called "multi site certificate." This alternative provides following pros and cons:

$\begin{array}{ll}- & \text { If one plant fail all the other does too } \\ - & \text { Person responsible for the cooperation needed } \\ -/+ & \text { Constant collaboration needed } \\ + & \text { Cost effective } \\ + & \text { Share information and tasks } \\ + & \text { Companies brand value retains } \\ + & \text { Less time consuming } \\ + & \text { Demands that all parts of the organization contribute to the goal }\end{array}$

3. The third alternative is that the Hub will apply for the certification together with SDLG. This alternative provides following pros and cons:

$\begin{array}{ll}- & \text { SDLG may not pass or be able to keep the certificate } \\ \text { - } & \text { Different way of working and different priorities } \\ \text { - } & \text { The VCE standardized processes may probably not be used } \\ + & \text { The VCE brand could lose value } \\ + & \text { Easier from the plants to be situated close to each other } \\ & \text { Less work for the Hub, with assumption that they can rely on the } \\ & \text { work }\end{array}$


What should international companies take into consideration in their environmental work when establishing on the Chinese market, and why?

- Regulations and requirements for both national and international companies taken by the Chinese government are not rooted in the broad opinion, resulting in that the regulations lack respect and authority among the Chinese people.

- Money invested by the government in environmental protection projects are easily "lost on the way", when passing different officials.

- Chinese companies will probably not adapt solely to international companies' strategies but rather adapt some parts and form their own strategies.

- Chinese companies do often have fewer resources available for environmental work.

- The transition phase, making Chinese companies more environmental-conscious, will take time. Just as it did when western companies started their transition phase years ago.

- The difficulties that an international company will meet can be reduced by knowing the regulations and requirements as well as the Chinese culture. Therefore good relations and the presence of knowledgeable Chinese employees are two very important rules in building a successful business in China.

- A key factor for success is to make people (in China) understand how important their own daily contribution is. It is also important for people to understand the importance of companies that show they take their environmental duties seriously. Knowledge-, technical- and attitude training is the key to success in this case. If you are introduced to a new way of thinking or a model, the best way to learn how to use it is to actively work with it and come up with solutions based on the new model, i.e., "learning by doing".

- The discrepancy between proactive and reactive work are not always clear in domestic companies in China. Problems are quite often dealt with reactively and finding the source to the problem is often not investigated.

- Training and mutual interchange between domestic and international companies is key success factors. 


\section{Recommendations}

The recommendations made are firmly established out of the information gathered during the work. Outgoing from that and my biased opinion the VCE Hub at Shandong Lingong can evolve their environmental work to reach Volvo standard doing following:

Hygiene factors:

\section{- Top management support}

-A GM that work close with the employees, shows that their opinion and work is important and gets feedback

- Training for the employees

-Both in respect of learning the way of working, understand the importance of the work and the risks with not taking the issues seriously.

- Awareness

-Important to run the work after the implementation and constantly improve it

- Knowledge about Chinese regulations

-To reduce difficulties in the daily work, make it less time consuming and minimize the risks for misunderstandings.

From my perspective a VCE employee specialized in environmental questions should have the duty of supporting SDLG. An organization with people from the line; purchasing, product development, and manufacturing should be the base for running the new EMS. This has proven to be a successful model as described in chapter 6.1.1 and 6.2.1. From my point of view hiring a consultant is not the best way of doing this implementation. There is a risk that a consultant company will build a system very quickly and when it is implemented their job is done. As so, there is a risk that the consulting company neglects a very important aspect - a governance model. To make a thriving implementation, attention and transparence in the organization is needed; otherwise no system could be kept alive and evolving afterwards. The board should appoint a VCE employee with experience from implementation processes of this kind. The person should have sustainable knowledge about VCEs environmental work and processes needed for change management as well as the Chinese culture and working climate. Most likely this person can be found within VCE but can also be at an external consultancy company if the contract states long-term support and cooperation with the environmental management team. I think the most important thing is that this person work dedicated in close collaboration with the VCE and SDLG personnel. Still the most preferable profile for this task is someone which also has good knowledge about VCE and "the VCE way of working".

How the Hub will be able to fulfill the demands in Volvo requirements for production sites, when several parts of the process are bought from SDLG, is an interesting aspect. In the steering document for suppliers it is said that the company should "act in accordance with the Volvo Group Environmental Policy and Volvo Code of Conduct". SDLG does not have an EMS that works to the extent that it is fulfilling Volvos minimum level, stated in the "Environmental requirements for Volvo sites". If SDLG, as a Volvo supplier, do not have a functioning EMS they will not be able to reach the requirements Volvo demands. This is resulting in that the Hub cannot reach the standard Volvo has set for their plants. To be able to meet the requirements SDLG has to improve the structure of their environmental work; implement an EMS, and start working pro-active instead of reactive. If the system is implemented in the Hub as a pilot project SDLG will be part of it, they can evaluate, and later 
an implementation in the whole SDLG could be possible. They learn how to work and will see the benefits of an implementation. SDLG could not be forced to do anything before 2012, but if they realize that it is a favorable way of working an earlier implementation may be possible. If SDLG have insight into the affairs of VCE, feel they are a part of the process, and have the possibility to make difference then it is more likely that they want to adapt the same system. SDLG will be much more prepared and closer to fulfilling the requirements when VCE takes over the year 2012. Understanding through all levels and communication is significant to build a sustainable system for environmental issues.

How to do with the certification ISO 14001 is another issue. Out of the three alternatives one could directly be rejected according to me; to certify the Hub alone will be too time consuming and expensive. It could of course be an alternative if no other ways were found but in this case it is not a preferable idea. To certify the Hub together with the rest of SDLG first seems like a good idea. It will show a good company relationship and attitude towards cooperation. SDLG have to improve a lot to reach Volvo Environmental standards, and that is mandatory if applying together. It will be goodwill for SDLG, since Volvo is a highly respected company. It could on the other hand be bad will for VCE because customers may be uncertain on the quality of the ISO work, since the two companies have different core values and environmental policies. The third alternative also seems like a good idea; to be certified together with another plant reduces the amount of work with legal authorities, VCE's EMS will not be compared with SDLG, and it will be moneysaving. The policies and EA though have to be rewritten to be suitable for both the factories. It will also increase the load of work for personnel working with these questions at VCEC. As mentioned before, a person responsible for the cooperation between the hub and VCEC will be needed. The extra workload that this cooperation generates is more than enough to justify the hiring of a new coworker in this section. This person could also be responsible for a dialog with SDLG concerning their environmental work and their adjustment to Volvo standards. 


\section{List of Sources}

Altin Elisabet, Business Contingency Manager,

Volvo Construction Equipment, Braas, Sweden. (personal communication Feb-May 2009)

Brorson T. och Almgren R. (2007), ISO 14001 for små och medelstora företag - utgåva 3, Stockholm, SIS förlag

Carre Bleuenn, Project Assistant, JEC Environmental Consulting, Shanghai, China. (personal communication Mars-April 2009)

CCAA, 2009, Certification and Accreditation Administration of the People's Republic of China Available at: http://219.238.178.8/20040420/column/227.htm, (Accessed 2009-03-09).

CCAA, 2009, Certification and Accreditation Administration of the People's Republic of China Available at: www.ccaa.org.cn/ccaa_en/int/47344.shtml, (Accessed 2009-02-03).

Chen Jack, Audit leader, SGS, Shanghai, China. (personal communication Mars-April 2009)

Chen Phil, TQM Manager, Volvo Construction Equipment (China) Co., Ltd, Shangahi, China. (personal communication Feb-May 2009)

Jiang Wei, Continuous Improvement Manager, Volvo Construction Equipment (China) Co., Ltd, Linyi, China. (personal communication Feb-May 2009)

Kjelltorp Hans, EHS manager, Sandvik, Zhenjiang, China. (personal communication Mars-May 2009)

Kvale, S. (1996), An Introduction to Qualitative Research Interviewing, Thousand Oaks, California, Sage

Lu JC, Safety \& Environment Manager, Volvo Construction Equipment (China) Co., Ltd, Shangahi, China. (personal communication Feb-May 2009)

McCracken, G. (1998), The Long Interview, California, Sage Publications

Million Dave, Vice President Order to Delivery, Volvo Construction Equipment (China) Co., Ltd. Lingong Integration Office, Linyi, China. (personal communication Feb-May 2009)

Naudin Aurore, Student, Tong-Ji University, Shanghai, China. (personal communication MarsApril 2009)

Page, M., Hair, Jr, J. H., Money, A.H., Samouel, P. (2007), Research Methods for Business, West Sussex, England, John Willey \& Sons Ltd

Rens Samantha, Project Coordinator, Idrabel Biological Technology, Shanghai, China. (personal communication Mars-April 2009) 
Rimaz Benoit, General Manager, Volvo Construction Equipment (China) Co., Ltd, Shangahi, China. (personal communication Feb-May 2009)

Sandvik, 2009, Code of conduct

Available at: www.sandvik.com (Accessed 2009-03-10- 2009-04-20)

Sandvik, 2009, Environmental dimensions

Available at: www.sandvik.com (Accessed 2009-03-10- 2009-04-20)

Sandvik, 2008, Sandvik Sustainability report 2008

Available at: www.sandvik.com (Accessed 2009-03-10- 2009-04-20)

SDLG, 2009, History Timeline

Available at: www.sdlg.cn/english/aboutus/History.htm, (Accessed 2009-02-03).

SDLG, 2009, Lingong Introduction,

Available at: www.sdlg.cn/english/aboutus/Introduction.htm, (Accessed 2009-02-03).

Shangdong Lingong, 2008. Shangdong Lingong 2008.

SIS, 2009, ISO 14001, Available at:

http://sis.se/DesktopOneCol.aspx?tabname=@ Amnlista\&CategoryType=AMN\&CategoryCode $=835 \&$ PresID=, (2009-01-19), ISO14001-serier.pdf $($ Accessed 2009-02-03)

Sjödin Per, Chief Engineer Powertrain Components, Volvo Construction Equipment (China) Co., Ltd. Lingong Integration Office, Linyi, China. (personal communication Feb 2009)

SKF, 2009, EHS Policy, Available at:

www.skf.com/portal/skf/home/sustainability?contentId=509029\&lang=en, (Accessed 2009-03-09).

SKF, 2009. Several documents were delivered by post which all were strictly internal and not for public printing.

SKF, 2009, SKF in China, Available at:

www.skf.com/portal/skf_cn/home/skfchina?contentId=079470\&lang=en,

(Accessed 2009-03-09).

SKF, 2009, This is SKF, Available at:

www.skf.com/portal/skf/home/about?contentId=000493\&lang=en, (Accessed 2009-03-09).

Swedishtrade, 2009, Kina, Available at:

www.swedishtrade.se, 2009/i_utlandet/landrapporter/kina.htm, (Accessed 2009-03-10).

UNEP, 2009, Environmental Management Systems in China,

Available at: www.unep.or.jp/ietc/focus/cn-EMS.doc, (Accessed 2009-03-09).

Volvo, 2009, VCEC Environment Management System Matrix

Volvo, 2009, The Volvo Way 
Volvo, 2009. Volvo Group and CE China brief

Volvo, 2009. Volvo CE Corp Pres 2008

Volvo, 2009. Volvo Group 2008

Volvo, 2009, Volvo Wanted Position and Minimum level

Wang Jianping, Chief Safety \& Environment, Shandong Lingong Construction Machinery CO., Ltd, Linyi, China. (personal communication Feb-May 2009)

Wang Yuluan, Waste water coordinator, Volvo Construction Equipment (China) Co., Ltd, Shangahi, China. (personal communication Feb-May 2009)

Welford R. (2001), Corporate Environmental Management, London, Earthscan Publications

Wu Lewis, EHS manager, SKF China, Shanghai, China. (personal communication Mars-May 2009) 


\section{Appendix}

\section{Appendix 1 - Volvo Wanted Position and Minimum level}

\section{Use of chemicals}

Minimum level:

- Health and environmental assessment of all chemical products used on site

- Inventory of all chemicals used on site

- Documented routines for storage, use and disposal of chemicals products

- Documented process for introducing new chemical products

- Implementation of black list requirements (Volvo Std 100-0002)

- Surveillance and possible replacement of chemicals and less hazardous alternatives must be introduced when technically and economically feasible (e.g.Volvo Std 100-0003 (grey list))

Wanted position

- Active programmes for substitution of environmentally hazardous products with less hazardous alternatives

- Active programmes to reduce the amount of chemicals used per produced unit

\section{Use of energy}

Minimum level:

- Energy mapping of all major energy utilisation processes

- Continuous action to improve the efficiency of energy utilisation

Wanted position:

Energy efficiency shall be a focus in the environmental improvement programs in all business operations and shall include active plans to reduce energy consumption per unit produced.

The contribution level should reflect the available potential but also recent years savings program should be considered i.e. the contribution may be less or more than the Volvo Group Target based on this evaluation.

\section{Emissions to air}

Sulphur in fuel

Max content (less than)

Minimum level

Wanted position:

NO $\mathrm{x}$ emissions

Max content (less than)

Minimum level

Wanted position:

$\begin{array}{llll}\text { Oil } & \begin{array}{l}\text { Natural gas } \\ \%\end{array} & \begin{array}{l}\text { Coal } \\ \%\end{array} & \begin{array}{l}\text { Biomass } \\ \%\end{array} \\ 1.0 & 1.0 & 1.0 & 1.0 \\ 0.1 & 0.1 & 0.1 & 0.1\end{array}$

Oil

$\mathrm{mg} / \mathrm{MJ}$

150

80

$\begin{array}{ll}\text { Natural gas } & \text { Coal } \\ \mathrm{mg} / \mathrm{MJ} & \mathrm{mg} / \mathrm{MJ} \\ 70 & 150 \\ 50 & 80\end{array}$

Biomass $\mathrm{mg} / \mathrm{MJ}$

100

90
TO $\mathrm{mg} / \mathrm{m} 3$ 100 
Emissions of volatile organic solvents (VOCs)

Minimum level:

- Solvent management plan

Wanted position:

Active substitution program to reduce emissions of VOC e.g. by use of materials with less content of organic compounds/solvents or by use of technical solutions such as processes changes.

\section{Emissions to water}

Minimum level:

The minimum level of performance refers to maximum allowed concentrations of the pollutants listed in the table below shall be reached unless legal exemption granted.

Wanted position:

To install water recycling processes and preferably with chemical recycling in closed loop processes

Pollutant

Cadmium

Mercury

Chromium, total

Chromium, hexavalent

Copper

Lead

Nickel

Silver

Tin

Zinc

Free cyanide

Halogens

\section{Maximum concentration, mg/l}

Minimum Wanted position (for direct discharge)

Organic effluents

Minimum level:

Process effluents with an organic content must undergo appropriate treatment before discharge to receiving waters

$\begin{array}{lll}\mathrm{Cd} & 0.1 & \text { ngw2 std } \\ \mathrm{Hg} & 0.05 & \text { ngw std } \\ \mathrm{Cr} \text { (tot) } & 0.5 & \text { ngw std } \\ \mathrm{Cr} \text { (VI) } & 0.1 & \text { ngw std } \\ \mathrm{Cu} & 0.5 & \\ \mathrm{~Pb} & 0.1 & \text { ngw std } \\ \mathrm{Ni} & 0.5 & \\ \mathrm{Ag} & 0.1 & \\ \mathrm{Sn} & 2 & \\ \mathrm{Zn} & 0.5 & \\ \mathrm{CN} & 0.2 & \\ \mathrm{~F}, \mathrm{Cl}, \mathrm{Br}, \mathrm{I} & 0.1 & \end{array}$

2 national ground water standard 
Wanted position:

Organic constituents in waste water should be focused with the ultimate target is to reach a waste water free process (e.g. closed loop process) or a waste water discharge (to receiving waters) free from organic contaminants.

\section{Waste management}

Minimum level:

- Sorting at source of all relevant waste and monitoring of quantities

- Development and implementation of measures to achieve improvements in:

- waste reduction

- materials recycling

- energy recovery

- minimizing landfill quantities

Wanted position:

- include waste contractors in ISO 14001 internal audit program

- normal landfill disposal restricted to include only inert (by reg. acceptance)materials

- reduce special landfill disposal

\section{Noise}

Minimum level:

$$
60 \mathrm{~dB}(\mathrm{~A})
$$

Wanted position:

$\begin{array}{ll}\text { Daytime } & 50 \mathrm{~dB}(\mathrm{~A}) \\ \text { Evening } & 45 \mathrm{~dB}(\mathrm{~A}) \\ \text { Night } & 45 \mathrm{~dB}(\mathrm{~A})\end{array}$

\section{Organization}

Minimum level:

- Appoint an environmental co-ordinator with adequate environmental competence

- Define environmental goals and actions

- Introduce an environmental management system in accordance with the general timetable for each business area

- Implement procedures/instructions/guidelines for handling (collecting, verifying and reporting), the environmental data for annual reporting to the Volvo Group

- Assess the environmental impact of new projects

- Investigate ways of decreasing the significant environmental impact of new projects

- Implement the environmental requirements for Volvo Group suppliers and contractors

- Require major suppliers to perform environmental self assessment

Wanted position: The same as minimum req.

(Volvo internal, 2009) 


\section{Appendix 2 - VCEC Environment Management System Matrix}

The departments' allotments and responsibilities for different requirements;

- Key department

$\diamond$ Related department

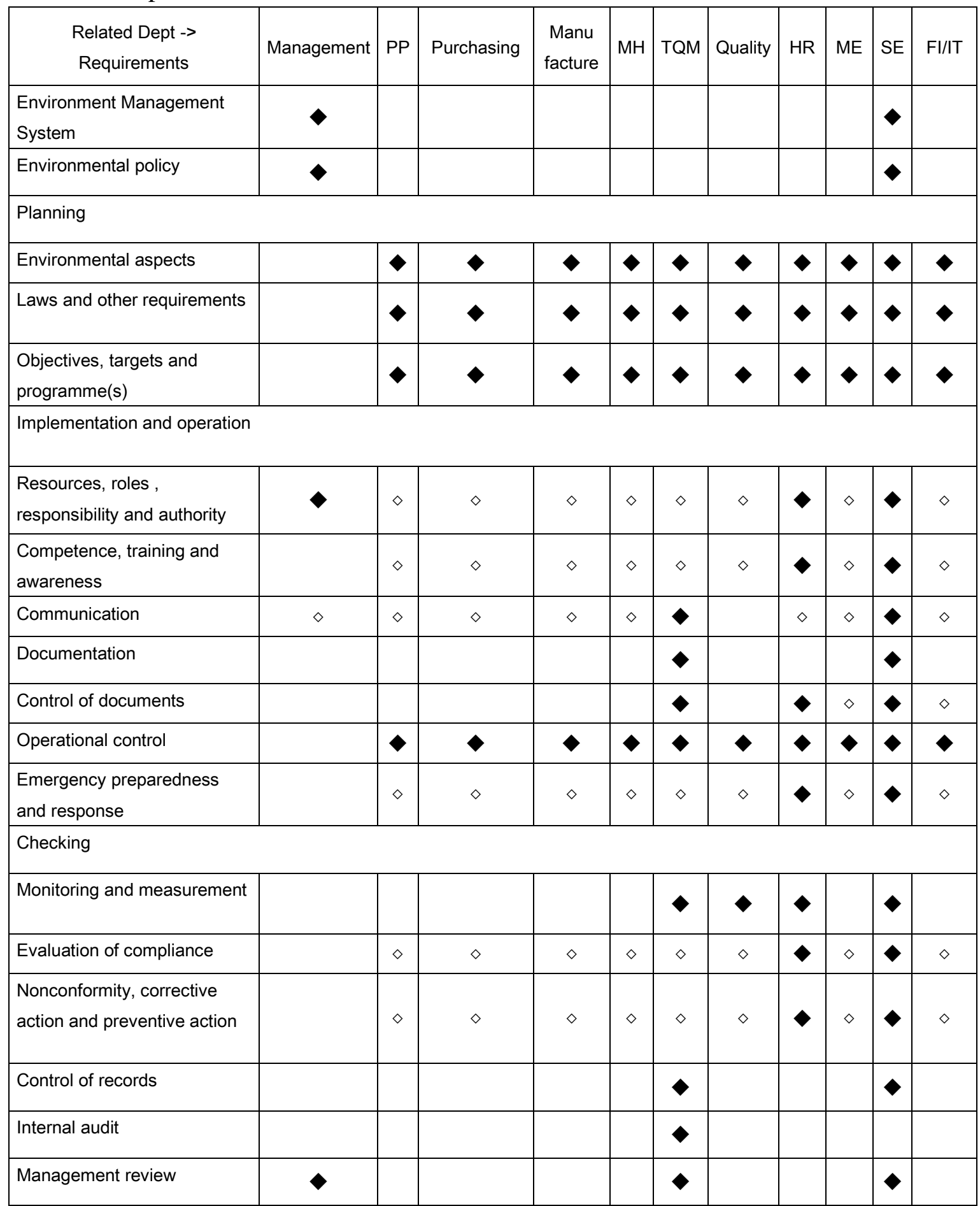

\section{Abbreviation}

PP:

$\mathrm{MH}$

Production Planning

Material Handling

ME: $\quad$ Maintenance \& Engineering

(Volvo Internal, 2009) 

TRITA-IM 2010:04

ISSN 1402-7615

Industrial Ecology,

Royal Institute of Technology

www.ima.kth.se 